Chapter 26

\title{
The Epidemiology of Paediatric Brain Cancer - Descriptive Epidemiology and Risk Factors
}

\author{
Adrianna Ranger \\ Additional information is available at the end of the chapter \\ http://dx.doi.org/10.5772/52427
}

\section{Introduction}

Cancer is the most frequently diagnosed disease-related cause of death among children and adolescents [1]. Of all paediatric cancers, those involving the central nervous system (CNS), and especially the brain, are collectively among the most common, ranking as the most common solid tumor and either first or second overall (second only to leukaemia) in the United States (USA) [1]- [5], Canada [6], and Mexico [7]. For example, in the USA in 2004, 555 cases of CNS cancer-related death were confirmed among children, and 566 for leukemia, representing $25.0 \%$ and $25.5 \%$, and therefore accounting, between them, for more than half of the total number of cancer deaths in individuals under age 20 [1]. Similar numbers through 2011 are published in an on-line report of the National Cancer Institute [5]. Since in excess of $90 \%$ of primary CNS cancers in children originate within the brain [4], from this point onward, this chapter will generally be limited to primary brain cancers. The American Brain Tumor Association has claimed that approximately 4,200 children younger than age 20 will be diagnosed with a primary brain tumor in the year 2012, of whom 3,020 will be under the age of 15 [8].

Survival rates from brain cancer have improved dramatically over the past forty years, presumably due to a combination of improved treatments and earlier detection [9]. However, there are concerns that the incidence of brain cancer has increased and/or is destined to increase due to the emergence of a host of new risk factors with almost universal exposure, especially in industrialized countries. Among these novel risk factors is the exponentially increasing use of hand-held electronic devices like cell phones, iPods, iPads and other electronic reading devices [10]- [12].

But is the incidence of brain cancer really increasing? Is this increase universal or just in certain countries and regions? Are these new devices playing a role? This chapter reviews the 
descriptive epidemiology of brain cancer in the paediatric age group, specifically looking at trends over time, followed by an examination of known and suspected risk factors. The first question is: Is the incidence of brain cancer really increasing?

\section{Descriptive epidemiology}

\subsection{The incidence of paediatric brain cancer: Trends over time}

Before discussing its incidence, it is necessary first to define what is meant by paediatric brain cancer. For the purposes of this chapter, only primary cancers of the brain will be considered, excluding metastases to brain from other sources, like lung and breast. Brain tumors are quite heterogeneous, in terms of both their histology and clinical course and prognosis. There also are exceedingly rare forms that stem from highly specialized cells, in addition to types that are more common. Most research on brain cancer has focused on the most common, which also tend to be the most lethal forms.

Cancers involving neurons themselves are quite rare, the majority of brain cancers involving cells that originate within the glial cell line [4]. Such glial cell cancers include astrocytomas in all their different forms and grades, from pilocytic astrocytomas to glioblastoma multiforme; oligodendrogliomas; other gliomas, and ependymomas. Primitive neuroectodermal tumors (PNET), which arise from primitive neuroectodermal tissues and include medulloblastomas, are another relatively common brain neoplasm that tends to arise in very young children; PNET account for approximately $20 \%$ of malignant CNS tumors in children [4]. Together, astrocytomas, oligodendrogliomas and other gliomas, ependymomas, and PNETs account for roughly $97 \%$ of all malignant paediatric brain tumors [4]. All remaining brain tumors are either very rare, usually benign, or both; and they all are especially uncommon in children. Primary CNS lymphomas that arise from the cells and tissues that comprise the CNS lymphatic system comprise one to two percent of all primary brain tumors, with patients whose immunity is compromised (e.g., AIDS patients and organ transplant recipients) at especially high risk. Other brain tumors that can be malignant but are usually benign include meningiomas, that are quite common, and pituitary and pineal tumors, which are much rarer, especially in children and adolescents. In this chapter, all brain cancers will be discussed; but the majority of research that has been conducted on risk factors for brain cancer in children has involved astrocytomas, oligodendrogliomas and other gliomas, ependymomas, and PNETs [4].

Despite its obvious importance as a medical issue, publications on general population studies (as opposed to case-control studies) assessing brain cancer incidence trends over time, and especially on its incidence in children, have been surprisingly rare. Almost all published general population data are at least a decade old, harkening back to a time when there was considerable concern that the incidence of brain cancer was increasing [4], [13]- [17]. Exceptions are longitudinal studies in the United Kingdom [18] and in India [19]. In the USA, between 1973 and 2001, the overall age-adjusted incidence of brain cancers was 6.1 cases per 100,000 person-years, of which roughly $46 \%$ (2.8 cases per 100,000 person-years) were the most malignant form, glioblastoma multiforme [13]. The 
incidence in children was 2.5 per 100,000 person-years. Overall, brain cancer rates increased steadily between 1973 and 1987, but then declined steadily afterwards; however, across all ages, the incidence of glioblastoma in 2001 was greater than the mean incidence over the 28 years of observation (3.0 versus 2.8 per 100,000). Though mortality across all brain cancers declined over the study period, survival did not improve for glioblastomas [13]. Data specifically on US children under age 15 between 1975 and 1995 reveal a clear increase in brain cancer incidence throughout the study period, rising from a low of under 2.5 per 100,000 person-years in 1975 and 1976 to highs of roughly 3.2 per 100,000 in 1987 and 1993 [4]. Further analysis of this trend identified, rather than a steady increase, a marked 'jump' in rate between the periods before and after 1985 [20], which corresponds to the marked increase in the availability of magnetic resonance imaging (MRI) for brain cancer detection in the mid 1980s and consistent with the lack of any significant increase in brain cancer mortality rate [4]. Interestingly, the noted increase was site specific, with incidence more than doubling in the brainstem and increasing by more than $50 \%$ in the cerebrum, but actually declining in the cerebellum and increasing by a mere $6 \%$ across all other sites [20]. Similarly, in the Northeastern U.S., certain brain cancers were noted to increase in incidence between 1954 and 1998 more than others, with annual increases of $1 \%$ in pilocytic astrocytomas, $1 \%$ in primitive neuroectodermal tumors, and $2.3 \%$ in miscellaneous gliomas [21].

The Surveillance Epidemiology and End Results database initially was created by the U.S. National Cancer Institute (NCI) in 1973 as the coalescence of 9 regional cancer registries to generate epidemiological data on cancer in the U.S. [22] It has since expanded to collect data on a broad array of cancers from registries representing $26 \%$ of the total U.S. population, and data on specific cancers are available for 1975 through 2009, including brain and other nervous system cancers [23]. SEER data demonstrate an overall incidence of brain and other nervous system cancers (invasive) of 5.85 across both sexes and all ages and races in 1975, with subsequent peak incidences of 6.51 in 1981, 7.05 in 1990, and 6.91 in 1999, with a gradual decline afterwards to 6.58 in 2009, for an overall incidence over the 35 years of data collection of 6.60 per 100,000 [24], and an average of 6.50 over the five years 2005 through 2009 [25]. Data by age are currently only listed for 2005 through 2009, and average 3.1 per 100,000 for those 19 and under, versus 19.6 for those 65 and older [25].

In other countries over roughly the same time period, roughly a $25 \%$ increase in cancer incidence was noted in Austria between 1970 and 2002, with mortality from brain cancer peaking in 2002 [14]; in Brazil between 1980 and 1998, age-adjusted brain cancer mortality rates across all age groups increased by approximately 50\% (from 2.24 to $3.3510^{5}$ ) [16]; in Norway between 1970 and 1999, the overall rate of brain and CNS tumors increased from 6.49 to 12.02 cases per 100,000 person-years, an $85 \%$ increase, with a trend of continuing increase from 1995-1999, especially in children 0-4 years old and in those 60 years and older [17]; and in India between 1982 and 2003, statistically-significant 3.1 to $4.7 \%$ increases in incidence were noted at three of five major centres (Mumbai, Bangalore and Chennai) for both males and females across all ages, while incidence remained stable in Delhi and Bhopal [19]. Over a somewhat earlier period, incidence and mortality from brain cancer rose significantly in Canada between 
1959 and 1987, though this was most marked in elderly males [26], and incidence doubled between 1948 and 1988 in New Zealand [27].

Contrary to these increases, in the United Kingdom between 1998 and 2007, no significant time trends were noted in overall incidence of brain cancers for either gender, or for any specific age group [18]. Site-specific increases were noted for the temporal lobe in men $(0.04$ new cases per year) and women (0.02 per year), accompanied by decreases in the rates of cancers involving the parietal lobe (-0.03 per year), cerebrum ( -0.02 per year) and cerebellum ( -0.01 per year), but in men only. The authors conjectured that the observed increase in the rate of temporal lobe cancers, if caused by mobile phone use, would constitute less than one additional case per 100,000 people over the observation period.

Consequently, though clear increases in the incidence of brain cancer were evident internationally into the 1990s, since that time there appears to have been relative stabilization, at least in the U.S and the U.K. Unfortunately, a lack of readily-accessible international data over the past decade precludes any assumptions beyond these two countries.

\subsection{Trends in mortality from brain cancer}

Brain cancer is the second leading disease-related (non-traumatic) cause of death among children and adolescents, behind leukemia, generally accounting for between 500 and 600 deaths per year in the USA since the year 2000 [1], [5]. However, in contrast with trends towards increasing incidence in many populations, overall there has been a decline in mortality from brain neoplasms over the past three to four decades, and this decline has been relatively continuous, even over periods of time when incidence has appeared to rise [4], [13], [20], [28]. In the U.S., this trend has been especially evident in children [4], [13], [20], [28], [29], with fiveyear relative survival rates from all brain cancers rising in those under age 15 from $59 \%$ between 1975 and 1984 to $67 \%$ between 1985 and 1994 [4] to over 70\% by 2012 [30]. In terms of absolute numbers, mortality rates from brain malignancies declined from 1.0 per 10 [5] children in the 1970 s, to 0.8 per 100,000 children in the 1990s, and then to roughly 0.6 per 100,000 from 2005 through 2009 in the SEER database [25].

Improvements in survival have been observed with certain neoplastic types much more than others, with survival rates from ependymomas increasing from 39 to $56 \%$ and from gliomas from 46 to $57 \%$ between these two time intervals. Overall improvements in survival generally have not extended to PNETs/medulloblastomas, with survival increasing only $3 \%$, from 52 to 55\% between 1975 and 1994 [4]. Nor have significant improvements been noted with glioblastomas [13], for which 1-year and 5-year survival rates have consistently fallen below thirtyfive and five percent, respectively [4], [13], [31], [32]. Fortunately, as previously stated, children are much more likely than adults to have low-grade astrocytomas, in particular pilocytic astrocytomas and other low-grade gliomas that are almost never fatal and often cured, depending upon their location and surgical accessibility [33]- [35]. They also are far less likely to have virtually universally-fatal glioblastomas than adults, in whom they are the most common brain tumor type [8], [35]. Diffuse pontine gliomas, which account for roughly 15\% of paediatric brain malignancies and arise anytime from infancy through adolescence, peaking in those between the ages of 7 and 9 years old, have a universally dismal prognosis, with 
median survival times of 12 months or less, irrespective of tumor grade; this is because their diffuse nature renders them unresectable [3] [6], and they tend to be unresponsive to either radiation or chemotherapy [37], [38].

At all ages, pediatric brain cancer survival rates have typically been much better than for adults [4], [13], a fact that largely can be explained by the much higher percentage of low-grade astrocytomas and gliomas, and much lower percentage of high-grade astrocytomas seen in children [8], [35]. Even among pediatric patients, however, survival rates vary with age, with older adolescents (ages 15 to 19) generally having fared better than children under age five, in whom low survival rates are especially noted for ependymomas and PNETs. This has been true not only in terms of current rates of survival (between 1986 and 1994, overall survival from all brain cancers was $77 \%$ in those 15 to 19 years old, versus just $45 \%$ in those under one year of age, and $59 \%$ in those between 1 and 4 years old), but also in terms of improvement in survival over time [4].

It must be considered, however, that long-term survival in children with brain cancer does not necessarily equal 'cure', and that low-grade neoplasms are not necessarily curable. How children do long-term is largely dependent upon the location and size of the tumor, its surgical accessibility, and its potential for re-growth [33], [34]. For example, even low-grade optic gliomas, localized brainstem gliomas, and medulloblastomas might never be cured, merely because of their location and associated high risks of surgical intervention. Moreover, even with lesions for which curative surgery is successful, considerable post-operative morbidity can result secondary to neurological damage caused by the tumor, especially if fast growing, and to the surgery itself [33], [34], [39]. Radiation therapy, classically used to de-bulk brain tumors prior to attempted resection, has been virtually contra-indicated in infants and preschool children, because of the adverse effects of radiation on the developing brain.

\section{Known risk factors}

\subsection{Demographic variables (age, gender, and race)}

Though relatively few data exist specifically addressing the association between various demographic factors and childhood brain cancers, the overall relationship between brain cancer incidence and mortality and patient age, gender and race have been well-established via a number of published studies [4], [13]- [19], [26]- [28], [40]- [42], as well as the SEER database [22]- [25]. In those under age twenty, age predicts not only overall incidence of and mortality from brain cancer, but also the incidence of and rate of survival from specific cancer types, and the risk of cancer at specific brain locations. From 2005 through 2009, the overall incidence of brain and other nervous system cancers was 3.7 per 100,000 in infants under one year of age, peaked to 3.9 in those 1 to 4 years old, and then steadily declined to 2.1 per 100,000 in adolescents between 15 and 19 [13], [25]. These numbers parallel earlier figures for 1986 through 1994, when incidence was 3.6 per 100,000 in infants, peaked to almost 4.0 by age 4 , and then steadily declined to under 1.7 per 100,000 by age 19 [4]. In terms of lesion location, 
cerebellar lesions were much more common in children nine years old and under, at 0.93 and 0.97 per 100,000 for those under 5 and 5-9 years old, respectively, than in older children, being just 0.37 per 100,000 in children over 15 [4]. Similar patterns were evident for brain stem lesions and brain sites other than the brainstem, cerebellum and cerebrum [4]. Cerebral lesions, however, predominated among those over age 10 (see Figure 1).

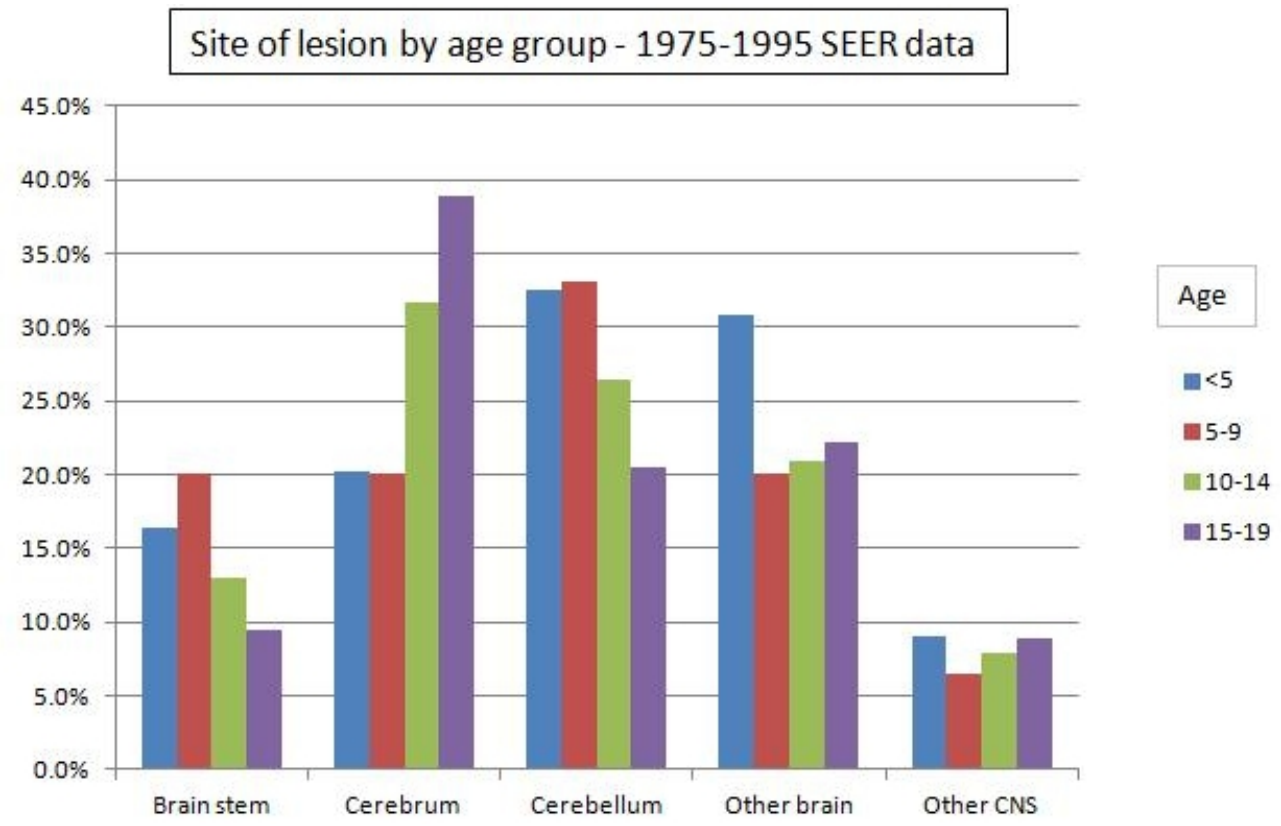

Figure 1.

Age also influences the types of brain cancer seen, especially in terms of ependymomas, most of which initially present in children under five years of age; and PNET, the incidence of which decreases steadily with age, from over 1.1 per 100,000 in the first year of life to roughly 0.2 per 100,000 in older teens [4]. The relatively poor prognosis of ependymomas and PNET, relative to the often low-grade gliomas and astrocytomas of childhood and adolescence, result in higher mortality rates among those under age five in both the U.S. and the U.K. [4], [41]; but other studies have also noted lower survival rates in younger versus older children with the same tumor; for example, low-grade astrocytomas [43] and ependymomas [41], [44].

Being male is considered a moderate risk factor for brain cancer. In the SEER database, over the entire period from 1975 through 2009, the incidence of CNS cancers was 7.90 per 100,000 in males versus 5.55 per 100,000 in females, and this disparity between the two sexes was evident every year, the rates being 7.72 and 5.60 per 100,000 in 2009 [24]. Over the entire time period, the incidence in males averaged $42 \%$ higher than in females, and this was relatively consistent. Similar population-based excess in brain cancers among males have been reported 
in Canada [26], the U.K. [18], Norway [17], Austria [14], India [19], New Zealand [27], and in 69 populations from a subset of cancer registries included in the Cancer Incidence in Five Continents database, in which male/female incidence rate ratios varied by age, but not by World Area, suggesting that the observed male versus female difference in brain cancer incidence is biologically based [45]. At least in the U.S. among children, this gender discrepancy largely is secondary to male predominance in certain neoplasms more than others, especially in medulloblastomas and ependymomas [4]. To date, however, no clear association between gender and cancer mortality rates has been established, especially among children.

Another very clear demographic predictor of brain cancer incidence, mortality, and type is race. Using the SEER database, between 1975 and 2009, whereas the overall incidence of brain and other nervous system cancers was 7.18 per 100,000 in whites, it was just 4.08 per 100,000 in blacks [24], 43\% lower. This discrepancy between the races persists over the most recent 5year data block from 2005-2009, in which the rates were 7.1 and 4.0 per 100,000 (44\% lower), respectively [25]. A similar difference is observed for mortality, with mortality rates among whites and blacks being 4.6 and 2.5 per 100,000 over the same 2005-2009 time period, making mortality from brain cancer $46 \%$ lower in blacks. The incidence of astrocytic glioma and medulloblastoma are particularly more prevalent in whites than blacks [46]. A similar low rate of brain cancer and brain cancer mortality, relative to Caucasians, has been identified for Hispanics and Asians. In California, for example, in data gleaned from the State Cancer Registry for 1988-1997, the odds of CNS cancer was 0.70 among blacks (i.e., $70 \%$ of the rate among whites), 0.64 among Asians, and 0.57 among Hispanics relative to Whites. [42] Not all non-Caucasian populations are protected, however. In New Zealand, at least as of 1988, the native Maori population exhibited a fourfold increase in their incidence of ependymomas versus Caucasians, as well as a significant overall increase in all brain cancers [27].

\subsection{Family history of cancer or other CNS disease}

As will be discussed in the next section, there is a clear association between certain familial syndromes and brain malignancy. Even beyond this, however, studies support an association between family history and brain cancer, albeit less conclusive than for age, sex and race, and generally for brain cancers in general and not just pediatric brain cancers. For example, Farwell and Flannery compared the occurrence of cancer in parents, siblings, and offspring of 643 patients who had had a CNS tumor in childhood, as recorded in the Connecticut Tumor Registry, with its occurrence among the parents, siblings, and offspring of 360 controls matched for sex, birth date, and birthplace [47]. Overall cancer incidence was comparable in the two groups, but 11 CNS tumors were identified in the relatives of cases, versus none in the relatives of controls $(\mathrm{p}=0.0005)$. The rate hematopoietic-lymphatic system tumors also was increased $(p=0.003)$. In addition, nine siblings of cases but only one sibling of a control had had cancer as a child. Medulloblastoma and glioblastoma multiforme were overrepresented in the group of children whose relatives had CNS tumors. Overall, a fivefold increase in CNS or hematopoietic-lymphatic malignancies was identified in cases versus controls.

In another study in which the nationwide Swedish Family-Cancer Database for the years 1958 through 1996 was used to analyze the risk of brain tumors in offspring ages 15-61 and siblings 
via parental cancer probands, among brain tumor patients, standardized incidence ratios (SIR) were statistically elevated to 1.7, 2.4, and 2.5 for all brain tumors, astrocytomas, and meningiomas, respectively. In addition, parental endometrial cancer and melanoma were associated with offspring astrocytoma, and parental breast and thyroid cancers with offspring ependymoma and neurinoma, respectively [48]. In a case-control study in Maryland, subjects with a family history of stomach cancer (odds ratio, OR, 2.2; 95\% CI, 1.0-4.6), colon cancer (1.4; 0.9-2.2), prostate cancer $(2.1 ; 1.1-3.8)$ or Hodgkin's disease $(2.4 ; 0.9-6.3)$ all had an increased odds of glioma [49], while increased risk of meningioma was noted among those reporting a family history of benign brain tumor (4.5; 1.0-21.0) or melanoma (4.2; 1.2-15.0), and a family history of breast cancer was associated with an elevated meningioma risk among subjects 18 to 49 years old, but not older (3.9; 1.4-11.0) [50].

More recently, using the Utah Population Data Base (UPDB), among first degree relatives of a proband with brain cancer, the relative risk (RR) was found to be almost 4 (3.8) for astrocytomas, 2.3 for glioblastomas, and 3.3 for both, each of these RR values statistically greater than 1.0; among second degree relatives, only astrocytomas had a relative risk greater than 1.0 (RR =1.9) [51]. Finally, in the Ohio Brain Tumor Study (OBTS), Ostrom et al. identified a significant association between a family brain cancer history and both malignant (e.g., malignant gliomas) and benign brain tumor subtypes, like meningiomas, acoustic neuromas, and pituitary adenomas [52]. Overall, the increased risk of brain cancer if a parent or sibling has had brain cancer has been estimated to be between 3 and 9-fold [4].

Some data also exist that support an association between brain cancer and a family history of epilepsy [53], [54], and between brain cancer and a family history of mental retardation [53], though these data are less conclusive. For example, in the 1991-1995 San Francisco Bay Area Adult Glioma Study, in which both personal and family histories were examined in 462 adults newly-diagnosed with glioma versus 443 controls, past epilepsy or seizures only were identified as a personal risk factor, the only family history risk factor identified being brain cancer, and only when both confirmed and probable family brain cancer cases were considered (OR 2.3; 95\% confidence interval 1.0-5.8) [55]. Cancer in general, and a host of other health conditions were not significant predictors of glioma cases, either in personal or family history.

\subsection{Genetics}

Central nervous system cancers occur within a broad range of familial clinical syndromes including what some consider the prototype CNS tumor syndromes - neurofibromatosis, types I and II - but also other skin conditions that, along with neurofibromatosis, are collectively known as the phakomatoses. These additional syndromes include disorders like tuberous sclerosis, Von Hippel Lindau Disease, and basal cell nevus syndrome. Other familial disorders have been clearly linked to increased CNS cancer risk as well, like Li-Fraumeni syndrome, a congenital condition linked to germ-line mutations of the p53 tumor suppressor gene, and familial polyposis disorders, like Turcot syndrome. Finally, this author has already published several papers describing the association between CNS tumors and dyschondroplasia syndromes, in particular Ollier's disease and Maffucci's syndrome. A list of this broad array of genetic familial syndromes associated with increased CNS tumor risk is provided below. 


\begin{tabular}{l}
\hline Phakomatosis syndromes \\
\hline$\bullet$ Neurofibromatosis (types 1 and 2, and segmental forms) \\
\hline$\bullet$ Tuberous sclerosis \\
\hline • Von Hippel Lindau disease \\
\hline Basal cell nevus syndrome \\
\hline Other familial syndromes \\
\hline - Li Fraumeni syndrome \\
\hline Pamilial polyposis syndromes (e.g., Turcot syndrome) \\
\hline Ollier's disease \\
\hline Maffucci's syndrome
\end{tabular}

Table 1. Familial Syndromes Associated with CNS Malignancies

\section{Neurofibromatosis and other phakomatosis syndromes}

The phakomatoses are characterized by the presence of pathological lesions involving the skin, eyes and central and peripheral nervous system (CNS) [56], all tissues of ectodermal origin. The phakamotoses otherwise share the features of being autosomal dominant, with variable expression but high penetrance; and all involving mutations of a tumor suppressor gene. Initially conceptualized by the ophthalmologist van der Hoeve in the early nineteenth century [57], they were assumed to primarily consist of three disorders: neurofibromatosis, tuberous sclerosis, and what we now know as von Hippel-Lindau syndrome. Over time, each of these three disease labels has been recognized as a collective term for multiple disorders; for example, neurofibromatosis is not one disease, but a collection of quite distinct diseases. On occasion, two distinct phakomatosis syndromes (for example, neurofibromatosis and tuberous sclerosis) have been described in the same patient [58]; but this is rare and may be the result of chance rather than some increased risk for both conditions. In terms of the current chapter, these three disorders, as well as more-recently described phakomatoses, share the property of being associated with an increased risk of malignancies involving the central and, sometimes, peripheral nervous system.

Neurofibromatosis (NF), which is now recognized not to be one, but at least two distinct disorders - neurofibromatosis type 1 (NF-1) and neurofibromatosis type 2 (NF-2) [59] - is the most common of all the phakomatosis syndromes, having been initially described by Frederick von Recklinghausen in the year 1882 [60]. Each of these two syndromes has its own diagnostic criteria that are very different; and whereas the characteristic lesion in NF-1 is the neurofibroma, the characteristic lesion in NF-2 is a peripheral nerve Schwannoma or neurolemoma [59], [61]- [63]. 
Neurofibromatosis type 1 (NF-1) is the most common form of disease, affecting one in roughly 2500 to 5000 live births [64]- [66]. This renders it more than ten times more common than NF-2 [64], [65]. Though autosomal dominant, up to $50 \%$ of cases arise spontaneously from a gene mutation that occurs on chromosome 17q11.2, which encodes for a large protein called neurofibromin [64], [66]. This NF-1 gene is a classical tumor suppressor gene, with tumor growth requiring the loss of BOTH alleles. Neurofibromatosis type 1 has a classical combination of clinical signs [67], for which the mnemonic CHANSOR has been used. These signs include Café au lait macules; Hamartomas of the iris (called Lisch nodules); Axillary and Inguinal Freckling; Neurofibromas; Skeletal lesions - like sphenoid wing dysplasia and thinning of long bone cortices; Optic gliomas; and in increased Risk of other CNS and systemic tumors. The disorder is diagnosed using National Institutes of Health (NIH) Consensus Criteria for the Diagnosis of NF-1 [65]. Besides the classic neurofibroma - which is generally an extra-cranial lesion that occurs both in paraspinal areas and in peripheral nerves [62], [67], [68] and, though benign, may transform into a neurofibrosarcoma - numerous other brain tumors are frequently observed in patients with NF-1. Most common are optic-hypothalamic gliomas, which manifest in roughly $15 \%$ of NF-1 patients. These lesions are categorized into those that involve just the optic nerve(s), lesions also involving the optic chiasm, and lesions that extend all the way into the hypothalamus. [69] Hemispheric and cerebellar gliomas are less common than lesions involving the optic tract [70]. Most are benign or only exhibit low-grade malignant potential; but all grades of malignancy have been reported [70]. Most are resectable. Brainstem gliomas also occur, as a heterogeneous group of lesions, with at least three main subtypes: (1) a diffuse area of brainstem enlargement; (2) focal enhancing nodules with or without cystic areas; and (3) peri-aqueductal gliomas. All subtypes generally have a very indolent course that usually does not require treatment, though MRI monitoring is indicated until their indolent course is confirmed. Some lesions regress on their own [70]. Though controversial, diffuse brainstem enlargement is presumed to represent gliomatous change, though these lesions have a more indolent course than brainstem gliomas seen outside of NF-1, such that adjuvant treatment only is required in that minority of patients whose lesions progress. This being said, these gliomas occasionally do progress to more malignant forms of astrocytoma, including glioblastoma [70], [71]. The focal enhancing nodules, with or without cystic areas, generally are thought to represent pilocytic astrocytomas, given their imaging characteristics. Like pilocytic astrocytomas elsewhere, they generally are indolent; but their course is unpredictable and the brainstem so susceptible to major deficits, relative to the cerebral hemispheres, that ongoing monitoring is required. Small, focal intrinsic lesions may enlarge and then regress spontaneously. Exophytic tumors often are more aggressive and require treatment.

Finally, peri-aqueductal gliomas occur adjacent to the aqueduct of Sylvius between the $3^{\text {rd }}$ and $4^{\text {th }}$ ventricles in the midbrain. They typically manifest with late-onset aqueductal stenosis, leading to hydrocephalus. Presumably, they represent low-grade gliomas or glial hamartomas, and typically are indolent. However, because of their location, shunting often is necessary. Resection is usually not necessary for any of the brainstem gliomas seen in NF-1 [70], [71].

Neurofibromatosis type 2 (NF-2) is much less common than NF-1, with a prevalence that has been estimated as roughly one in 25,000 to 50,000 [64], [65], [67]. NF-2 is caused by a mutation 
affecting chromosome 22q12 and the gene product merlin (a moesin-, erzin-, and radixin-like protein), which sometimes is called schwannomin. Merlin encodes for a polypeptide that may affect cell growth and motility; more interesting, in terms of its presence in NF-2, is that it is a tumor inhibitor that often is absent in brain tumors [72]- [74]. In addition, the same chromosomal abnormality is found in spontaneous spinal schwannomas, which suggests that a single location causes Schwann cell tumor growth [75]. Clinically, NF-2 is a combination of features that always entails at least one eighth cranial nerve (CN-VIII) neurilemoma, in addition to a variety of other tumors (e.g., neurofibromas, meningiomas, gliomas, neurilemomas), juvenile posterior sub-capsular cataracts, and occasional other lesions like café au lait spots. Like NF-1, it is diagnosed using NIH Consensus Criteria, initially proposed in 1988 [76], but modified in 1997 [77]. Cranial nerve neurolemomas, especially of the eighth cranial nerve (CN-VIII), are the hallmark lesion of NF-2, with CN-VIII lesions present in roughly $95 \%$ of patients with NF-2; when bilateral, they are diagnostic of NF-2 [63], [67]. As a rule, spinal lesions are more common in NF-2 than in NF1, while brain lesions are less common in NF-2 than NF-1. In NF-2, this includes extracranial neurilemomas and meningiomas. But also among the various tumors are brain neoplasms, particularly ependymomas that are the most common malignancy in NF-2, versus astrocytomas in NF-1 [62], [63], [70]. These ependymomas usually are well-circumscribed, and therefore often quite resectable. Their surgical and post-operative management (like the use of adjuvant therapy) is the same as for intramedullary spinal tumors in patients without neurofibromatosis.

Tuberous sclerosis, which also is called tuberous sclerosis complex (TSC) and Bourneville's disease, is the second most common phakomatosis syndrome, after neurofibromatosis type 1 . It affects anywhere from one in 6000 to one in 30,000 people [78]- [80], with marked variations in penetrance rendering all estimates somewhat unreliable. The syndrome is autosomal dominant, but up to $60 \%$ of cases arise from spontaneous mutations [78], [80], [81]. Two tumorsuppressor genes, TSC-1 (tuberous sclerosis complex-1) and TSC-2, are responsible for TS. Roughly $80-90 \%$ of mutations involve TSC-2, while just $10-20 \%$ of mutations involve TSC-1 [81]. The genetic locus for TSC-1 is chromosome $9 \mathrm{q} 34$, and the TSC-1 gene product is called hamartin. The genetic locus for TSC-2 is chromosome 16p13.3, and the TSC-2 gene product is called tuberin. Both hamartin and tuberin appear to have roles in cell differentiation, proliferation and migration. The disorder effects cellular differentiation, proliferation and migration during early development, leading to various diffuse hamartomas and neoplastic lesions that can affect virtually any body organ [81], [82]. It can present at any age, but most commonly appears during childhood, especially late childhood. Though skin, heart, lung and renal involvement are common, neurological involvement is the most common cause of morbidity and mortality from TS, and the most common cause of death in patients under 30 years old. Problems stem from a broad variety of intra-cerebral tumors, which include cortical tubers, subependymal nodules, and subependymal giant cell astrocytomas (SEGA). Subependymal giant cell astrocytomas develop in between 5 and 15\% of TS patients [83], typically developing in the region of the foramen of Monro, where they frequently cause obstructive hydrocephalus. Though they are slow-growing and rarely undergo malignant transformation, these tumors are problematic because of their location and relative inaccessibility for resection. Death 
primarily results from intractable seizures or SEGA-induced obstructive hydrocephalus; and, overall, the long-term prognosis is poor.

The average age at first presentation with Von Hippel-Lindau Disease is 26 years, and the average age at diagnosis 31 [84]. Nonetheless, pediatric cases are not uncommon. Von HippelLindau disease is autosomal dominant, with $97-99 \%$ of cases familial and only 1-3\% occurring as a result of spontaneous mutations. It is associated with inactivation of the tumor-suppressor gene VHL (Von Hippel Lindau), which is found on chromosome 3p25 [84], [85]. Decreased levels of the VHL protein, which is important in a critical pathway helping cells to adapt to hypoxic stress, lead to over-expression of a hypoxia-inducible transcription factor (HIF-1) which, in turn, results in increased cell proliferation, and the over-expression of several growth factors, ultimately manifesting as multiple, multi-systemic benign and malignant tumors, which sometimes are bilateral (e.g., both eyes) [86]. These tumors include haemangioblastomas of the cerebellum, spine, brainstem and retina (the most common tumor identified); renal clear cell carcinomas; pheochromocytomas; pancreatic and renal cysts; endolymphatic sac tumors (ELSTs, of the petrous bone at the cerebellopontine angle) [87]; papillary cystadenomas of the epididymus or broad ligament; and haemanigiomas of the adrenal glands, liver and lungs. As with all the other phakomatosis syndromes, the diagnosis is made on clinical grounds using established, published criteria. Central nervous system manifestations are highly prevalent [88], [89], with CNS haemangioblastomas occurring in 60 to $80 \%$ of patients. Moreover, they are more likely to be multiple and present at an earlier age than when they occur sporadically, being a presenting feature in roughly $60 \%$ of VHL patients [90]. These lesions may occur anywhere along the cranioaxial axis, but only $1 \%$ of these tumors are supratentorial [90]. The site of lesion determines the symptoms with which the patient presents. The cerebellum and brainstem are the most common sites of haemangioblastomas in VHL syndrome [90], where patients present with headaches, vomiting, lethargy, dysmetria, ataxia, papilloedema, polycythemia from tumor production of erythropoietin, and/or enlarging cysts that may cause brainstem compression (solid tumors generally do not cause such compression in VHL syndrome).

As with almost all the phakomatoses, basal cell nevus syndrome (BCNS) is autosomal dominant, the offending gene, called PTCH1, localized to chromosome $9 \mathrm{q} 31$ in about $85 \%$ of cases. The PTCH1 gene product is a trans-membrane receptor that binds to and regulates a protein called Sonic the hedgehog homolog $(\mathrm{SHH})$, one of three proteins in the mammalian signalling pathway family called 'hedgehog', and one which plays a key role in the regulation of organ development in vertebrates, including the growth of fingers and toes and the organization of the central nervous system. It also controls cell division in adult stem cells and has been implicated in oncogenesis. Mutations in the PTCH1 gene result in uncontrolled SHH activation [91]. This rare condition, which affects roughly one in 50 to 60 thousand live births [84], is characterized by multiple basal cell cancers, often presenting in adolescence. Despite the relatively innocuous-sounding name, there is a wide range of non-neurological manifestations, including numerous other benign and malignant tumors, both non-CNS and CNS, including melanomas, leukaemia, lymphoma, lung and breast cancers, medulloblastomas, and 
meningiomas [92]. Like virtually all the familial cancer syndromes, basal cell nevus syndrome is diagnosed using diagnostic criteria.

\section{Other familial syndromes associated with CNS malignancies}

Other familial syndromes associated with paediatric CNS malignancies include Li-Fraumeni Syndrome (LFS), a very rare autosomal dominant disease that is caused by a germ line mutation of chromosome 53 in roughly $70 \%$ of families in which the syndrome is diagnosed [93]. Patients exhibit a variety of carcinomas and sarcomas, including premenopausal breast cancers, osteosarcomas, soft tissue sarcomas, acute leukaemia, cancer involving the adrenal cortex, and primitive neuroectodermal tumors (PNET) like medulloblastoma. This increased risk of several malignancies likely stems from deactivation of p53, which normally controls apoptosis and the repair of damaged DNA. Patients present not only with a variety of cancers, but with cancers at a very early age, with the mean age at presentation of brain tumors being 25 years. The diagnosis of so-called 'classic LFS' is made in any patient under 45 years who presents with a bone or soft-tissue sarcoma, plus one first-degree relative who presents with any cancer before age 45 , plus one further first or second-degree relative of the same lineage who has had any cancer before age 45 or a sarcoma at any age [94]. More recently, a related syndrome, called Li-Fraumeni-like syndrome, has been described, defined as a proband with any childhood tumor or any sarcoma, brain or adrenocortical tumor before 45 years of age, who has a first- or second-degree relative with any cancer before the age of 60 [95], [96]. Interestingly, whereas p53 germ-line mutations are found in $70 \%$ to $80 \%$ of families with classic Li-Fraumeni syndrome, they only are identified in between $20 \%$ and $40 \%$ of families with LiFraumeni-like syndrome $\left[8^{\left[{ }^{[4]}\right.}\right.$. The CHK2 checkpoint homolog gene, CHEK2, which is located on the long (q) arm of chromosome 22, also has been implicated in some families with classic Li-Fraumeni syndrome. Recently, mutation of another gene, which encodes for the breast cancer 2 (BRCA2) susceptibility protein, has been found with increased frequency in the nonclassic syndrome [96]. It should be noted that p53 mutations are rare in sporadically occurring medulloblastomas. Overall, about $10 \%$ of LFS patients will develop a glioma before the age of 45 , and another $5 \%$ a supratentorial primitive neuroectodermal tumor (PNET), like a medulloblastoma, or choroid plexus carcinoma [97].

A Canadian surgeon named Jacques Turcot is accredited with having characterized Turcot syndrome, one of the several familial polyposis syndromes associated with familial, in this case autosomal recessive, inheritance and the presence of multiple colonic adenomas and adenocarcinomas [98]. An additional feature of Turcot syndrome is its association with several different neuroepithelial tumors of the central nervous system, including astrocytomas, medulloblastomas, pineoblastomas, gangliogliomas, and ependymomas [84]. Turcot syndrome has been categorized into types 1 and 2, with type 1 characterized by glioblastoma, no familial adenomatous polyposis, but often hereditary nonpolyposis-related colorectal carcinoma. Germ-line mutations in a few DNA mismatch repair genes - PMS2, MLH1 and MSH2 - are associated with type-1 Turcot syndrome. Interestingly, type-1 Turcot syndrome also is associated with café au lait spots [84]. Con- 
versely, type-2 Turcot syndrome families have medulloblastomas as their most common CNS malignancy, and multiple adenomatous polyps that often undergo malignant transformation [99]. Unfortunately, medulloblastomas, glioblastomas and anaplastic astrocytomas are the most common CNS tumors observed in Turcot's syndrome, the three combined accounting for 95\% of all CNS tumors in these families [100]; and the latter two are inevitably fatal. In addition, they tend to occur early, with medulloblastomas typically diagnosed in children less than 10 years old, and gliomas in those under age 30 [84], [101]- [103]. As such, and because some die of metastatic colon cancer that sometimes presents quite early in childhood or the second decade of life, many die as adolescents or young adults. In one tragic case, for example, doctors in Pittsburgh reported the case of a girl who developed a medulloblastoma at the age of 5 years. Ten years later, she developed adenocarcinoma of the colon. Then, seven months after resection of a Dukes' C2 adenocarcinoma, she presented with a second primary CNS tumor, this time a glioblastoma multiforme [101].

Rubenstein-Taybi syndrome is an autosomal dominant disorder that is associated with numerous anatomical/functional abnormalities that include abnormal facies, microcephaly, broad thumbs, big toes and moderate to severe intellectual impairment. There also is an increased incidence of neuroepithelial tumors - in particular medulloblastomas, meningiomas, and oligodendrogliomas [104], though other CNS tumors have been described [105]. A germline mutation in one allele of CRE binding protein (CBP, a transcriptional co-activator for several c-AMP regulated genes) has been implicated in many cases. CBP binds to the activated form of GLI, a transcription factor that is important in the regulation of the Sonic the hedgehog homolog $(\mathrm{SHH})$ that, as stated earlier, controls cell division in adult stem cells and has been implicated in oncogenesis. The GLI gene is downstream of the PTCH1 gene that is mutated in basal cell nevus syndrome.

\section{Ollier's disease and Maffucci syndrome}

Enchondromatosis, also called dyschondroplasia, is a hamartomatous proliferation of chondrocytes within the metaphysis of bone [106]. Though often asymptomatic and only diagnosed as an incidental X-ray finding, it can lead to significant deformities, reduced bone length [107], [108], and occasional pathologic fractures [108]. Moreover, just like the phakomatoses and familial syndromes like Li-Fraumeni and Turcot syndrome, enchondromatosis appears to confer a substantial increased risk of a variety of CNS and other malignancies, at least through the sixth decade of life and as early as the first decade. These tumors include chondrosarcomas that result from sarcomatous transformation of the enchondromas themselves, as well as other histologically-distinct malignancies like angiosarcomas, osteosacrcomas, ovarian tumors, various leukaemias, and a variety of glial-cell based central nervous system tumors (ranging from stage I to stage IV astrocytomas) [109]. This association with malignancy appears to be particularly true in instances of multiple enchondromatoses, as in Ollier's disease and Maffucci's syndrome [110], two very rare conditions [111], [112]. 
Since Boinet first reported CNS malignancy in a patient with multiple enchondromatosis, [113] 45 additional patients with either Ollier's disease (OD) or Maffucci's syndrome (MS) and some form of intracranial malignancy have been reported in the medical literature, ranging from 6 to 58 years old [114]. Ollier's disease patients appear to contract their neoplasms at a particularly early age, including very young childhood [109], [114], [115]. What causes this persistent increase in malignancy potential is not yet known. We do know that single enchondromas, outside some greater syndrome, are associated with an elevated risk of malignant change. Altay et al [116], for example, conducted an 18-year retrospective analysis of 627 cartilageforming benign bone tumors, and found that 32 patients had experienced malignant transformation, with 14 of these 32 patients initially having had a solitary osteochondroma, ten multiple osteochondromas, six a solitary enchondroma, one Ollier's disease, and one Maffucci's syndrome. The one patient with Ollier's disease had two chondrosarcomas; and the single patient with multiple osteochondroma had three chondrosarcomas. The overall rate of malignant transformation for cartilage-originating tumors was $5.1 \%$, being $4.2 \%$ for solitary osteochondromas, $9.2 \%$ for multiple osteochondromas, and $4.2 \%$ for solitary enchondromas. A variety of chromosomal abnormalities also have been reported in isolated cases of OD or MS and chondrosarcoma. These abnormalities include, for example, the interstitial deletion, del(1)(p11p31.2), as the only chromosomal abnormality identified in a low-grade chondrosarcoma in a patient with Ollier's disease [117]. Also, Bovée et al [118] identified (1) the loss of heterozygosity $(\mathrm{LOH})$ in a tibial chondrosarcoma and its metastases, exclusively on chromosome bands 13q14 and 9p21, with the LOH not identified in a femoral enchondroma that was analyzed; and (2) p53 over-expression in a tibial chondrosarcoma and its metastases, not present in a femoral enchondroma. Meanwhile, Chang et al [119] identified identical male twins with OD who both developed astrocytomas within their cerebral cortex during their early twenties; and Robinson et al [120] found evidence of mitogenic neurotransmitters within both enchondromas and soft tissue hemangiomas in a patient with Maffucci's syndrome, implying that the bone and vascular lesions, and possibly malignant tumors, might be related to an underlying neural abnormality. Having said all this, to date, no consistent chromosomal abnormalities have been identified in these patients, and all theories regarding the cause of malignancies in these syndromes remain unproven.

\subsection{Ionizing radiation}

The first report of a radiation-induced CNS tumor was by Mann et al in 1953 [121]. He described the case of a 3 year-old girl, born in 1942, who presented with a left optic nerve astrocytoma that was excised and then irradiated with a total dose over time of 6,500 rads. Six years later, at age 9, she presented with her first episode of recurring frontal meningiomas, which subsequently underwent malignant change, leading to her death at age 10. At about the same time, two independent groups were reporting on the 1.5 to 2-fold increased risk of cancers, including brain cancers, in children exposed to X-rays in utero [53], [122]- [124]. Subsequently, more than 280 radiation-induced intracranial tumors have been reported in the literature, the most common being meningiomas, sarcomas, and gliomas, though ependymomas, Schwannomas, PNETs, and pituitary adenomas have been described as well [125]. Consequently, the association between therapeutic radiation to the head and the subsequent risk of brain cancer 
has been well-established, especially since a landmark study performed in Israel and published in 1988 [126]. In this study, the relationship between radiotherapy in childhood for tinea capitis and the later development of tumors of the brain and nervous system was evaluated in 10,834 patients treated between 1948 and 1960. Benign and malignant tumors were identified from the pathology records of all Israeli hospitals and from Israeli national cancer and death registries. Doses of radiation were estimated retrospectively for each patient (mean, 1.5 Gy). The incidence of tumors was 1.8 per 10,000 persons per year, and the estimated relative risk (RR) versus 10,834 matched general-population controls and 5392 non-irradiated siblings 6.9 (95\% confidence interval 4.1-11.6) for all tumors and 8.4 (4.8-14.8) for neural tumors of the head and neck. Increased risks were observed for meningiomas ( $R R=9.5)$, gliomas (2.6), nervesheath tumors (18.8), and other neural tumors (3.4). Moreover, a strong dose-response relationship was identified, with relative risk approaching 20 beyond estimated doses of 2.5 Gy. Radiotherapy also was associated with an increased risk of death from tumors of the head and neck, including brain cancers $(R R=3)$ and leukemia $(R R=2.3)$ [127].

In an earlier case-control study, 2,215 patients in New York who during childhood had been given x-ray therapy for tinea capitis between 1940 and 1959 were compared against 1,395 persons matched for age, sex, and race and also treated for tinea capitis over the same period without x-ray therapy [128]. Excess incidence was noted in irradiated cases of tumors of the head and neck, including the skin, brain, thyroid, and parotid. However, there was no increased mortality from malignant neoplasms or any other cause. In another study, diagnostic X-rays of the head and neck increased the odds of brain tumors by $64 \%$ (OR 1.64; 95\%CI, 1.04-2.58). [129] Thierry-Chef et al has estimated that the life-time increase in brain cancer risk among pediatric patients receiving radiation to the brain ranges from 2 to $80 \%$, depending upon the dose and conditions of exposure [130]. There is, however, a huge range in the latency time between irradiation and subsequent brain tumor development, from 4 to 47 years among 27 cases described by Chowdhary et al. [125] Clearly, some such tumors may arise in childhood, and others much later.

\section{Suspected/possible risk factors}

In addition to risk factors that have been established through consistent results across several studies, there are several suspected or possible risk factors for which data are either scarce or conflicting. Difficulties that arise from the study of these risk factors include their somewhat ubiquitous exposure (e.g., electromagnetic fields), difficulties measuring exposure (e.g., diet, parental occupation), and their relative novelty (e.g., cell phones and other hand-held electric devices).

\subsection{Electromagnetic fields}

Over the past few decades, considerable research has been compiled supporting the association between electromagnetic field (EMF) exposure and childhood leukemia, such that the International Agency for Research on Cancer has classified extremely-low-frequency magnetic field 
exposure as a possible human carcinogen [131]. However, data linking EMF exposure and brain cancer are much less conclusive [131]- [135]. Most older studies suffered from various methodological issues, like the problem of inadequate blinding of those evaluating EMF exposure, and crude measurements of actual exposure [53]. The first studies to overcome these short-falls were conducted in Denver, Colorado by Savitz et al. who, in their initial study, had blinded assessors evaluate the power-line configurations of the homes of all 356 residents in the five-county 1970 Denver, Colorado Standard Metropolitan Statistical Area between 0 and 14 years of age who had been diagnosed with any form of cancer between 1976 and 1983; among them were 59 confirmed cases of brain cancer [136]. The odds ratio comparing very high and high wire codes versus very low, low, and buried wire codes was 1.5 (95\% CI $=1.0-2.3$ ) for total cases, with $\mathrm{OR}=2.0$ for brain cancer. Subsequently, this same group studied the effect on childhood cancer of prolonged exposure to $60-\mathrm{H}$ magnetic fields from electric appliances comparing Denver area children 0-14 years old whose incident cancers had been diagnosed between 1976 and 1983 versus controls selected by random digit dialing, matched for age, sex, and telephone exchange area. Parents of 252 cases and 222 controls were interviewed at home about the use of electric appliances by the mother during pregnancy (prenatal exposure) and by the child (postnatal exposure). After adjusting for income, prenatal electric blanket exposure was associated with a significant increase in the incidence of childhood brain cancer $(\mathrm{OR}=2.5$, 95\% CI 1.1-5.5) [137]. Subsequently, Savitz et al assessed for risk in the same Denver population by comparing risks by high wire code (HWC) versus low wire code (LWC) classifications using the Wertheimer-Leeper coding method, modified by eliminating the distinction between thick and thin primaries, distinguishing only between open and spun secondaries, and reducing the number of categories from five to three [138]. The association between the modified code and measured magnetic fields was similar to the association with the original wire code. Residences assigned the high wire code had odds ratios of 1.9 for total cancers (95\% CI: 1.1-3.2), 2.9 for leukemias (1.5-5.5), and 2.5 for brain cancer (1.1-5.5), after adjusting for all other measured potential risk factors for childhood cancer.

In 2001 [134] and again in 2010 [139], Kheifets et al reviewed all major studies published on the association between EMF and childhood brain cancers published to date and found that, where the earlier studies by investigators like Wertheimer and Leeper [140], Savitz et al [136][138] and Tomenius [141] identified an association between EMF exposure and increased brain cancer risk, later studies and reviews by investigators like Preston-Martin et al [142], Gurney et al [132], Feychting et al [143], Kheifits et al [133] generally failed to confirm this risk. In their 2010 meta-analysis of brain cancer risk with extremely low-frequency EMF, Kheifits et al subdivided studies in terms of both the methodology of EMF measurement (long-term, calculated fields, or spot measurement) and the type of home exposure (home at the time of cancer diagnosis, longest-lived-in home, and birth home) and found no significantly elevated odds ratios for any of the six categories, even with exposures $\geq 4 \mu \mathrm{T}$ [139]. This conclusion, that there are no conclusive data linking EMF exposure with brain cancer risk has been echoed by others [144], [145].

Relatively few papers have looked at the use of computers, per se. Both Mutnik et al and Wood specifically assessed the risk of computer use in terms of brain cancer development, and neither 
identified any significant risk [146], [147]. However, both papers were written in the 1990s, before the recent surge in home computer use, and long before prolonged exposures (e.g., 10 years or greater) to home computers could have occurred.

In one clever paper in which the pros and cons of the association between EMFs and childhood brain cancer were debated by two teams, each composed of eight international experts, using 12 pre-determined questions, arguments on both sides ultimately concluded that further research is necessary, an opinion vigorously championed by Carpenter in his paper Electromagnetic fields and cancer: the cost of doing nothing [10]. However, contributing to the confusion regarding EMF exposure are a number of methodological issues pertaining to the measurement of EMF, both in and around residences and in the workplace, issues that have sparked almost as much debate and research as the question of EMF exposure's role in disease [143], [148]- [154]. Such issues include questions about the accuracy of EMF measurements, how to avoid bias in subject selection, where best to measure EMF exposure (e.g., a child's bedroom versus elsewhere in or around the home), how to deal international variations in wiring techniques, how to interpret changes in electrical wiring over time and their effects, and how to adjust for the myriad of other potential confounders like other household exposures and exposures, EMF and otherwise, outside of the home. This last issue is, in fact, a problem with virtually all of the suspected or potential risk factors that are discussed here, including cell phones and other hand=held electronic devices, which are the topic of the next section.

\subsection{Cell phones and other hand-held devices}

Over the past 15 years, there has been a virtual explosion in the use of hand-held cellular devices like cell phones, iPods, iPads, Kindles, and other electronic reading devices. For example, whereas uncommon in use in 1995, as of 2011, there were more than 4.6 billion active mobile telephone subscriptions worldwide [155]. This has led to considerable concern regarding the impact such devices might have upon health and, in particular because of the issues raised with EMFs, upon brain cancer and leukemia rates.

Over the last decade, most data on cell-phone use and cancer risk have come from the 13country INTERPHONE Study, and from Sweden, and the results from these two sources have been somewhat conflicting. In Sweden, most of the data has been collected by the research group of Hardell et al. [129], [156] In their most recent study, analysis was performed pooling data from two case-control studies on patients with malignant brain tumors diagnosed from 1997 through 2003 compared against matched controls alive at the time of study inclusion, and a third case-control study on deceased patients and controls diagnosed over the same time period [157]. In total, 1,251 (85\%) cases and 2,438 (84\%) controls were identified. Brain cancer risk was noted to increase with latency period and cumulative use in hours, both for mobile and cordless phones. The greatest level of risk was identified for astrocytoma, the odds ratio (OR) for the longest (>10 year) latency group for mobile phone use equal to 2.7 (95\% CI, 1.9-3.7) and for cordless phone use 1.8 (1.2-2.9). The risk of astrocytoma was highest in the group with first use of a wireless phone before the age of 20 (mobile phone use $\mathrm{OR}=4.9,95 \% \mathrm{CI}=2.2-11$; cordless phone use $\mathrm{OR}=3.9,95 \% \mathrm{CI}=1.7-8.7$ ). Earlier, Hardell et al had reported on their comparison of mobile phone use in deceased brain cancer cases relative to controls who had 
died from another type of cancer other than brain tumor, and to controls who had died from other diseases. Exposure was assessed by a questionnaire sent to the next-of-kin. Replies were obtained for 346 (75\% participation rate) cases, $343(74 \%)$ cancer controls and $276(60 \%)$ controls with other diseases. Use of mobile phones was associated with an increased risk of brain cancer that was highest in the >10-year latency group, with an odds ratio of 2.4, (1.4-4.1). The risk increased with cumulative number of lifetime hours for use, and was highest in those with more than 2,000 hours of mobile phone use $(\mathrm{OR}=3.4 ; 1.6-7.1)$. No clear association was found for the use of cordless phones, though OR was 1.7 (0.8-3.4) among those with $>2,000 \mathrm{~h}$ of cumulative use [158]. These findings were interpreted as supporting earlier findings by this group in other studies.

The INTERPHONE Study has been a multinational case-control study designed to investigate whether mobile phone use increases the risk of cancer and, more specifically, whether the RF fields emitted by mobile phones are carcinogenic [159]. As such, the study has focused on tumors that arise within those tissues most exposed to the RF fields emitted by mobile phones on the same (ipsilateral) side as phone use. In addition to collecting detailed histories on mobile phone use, information has been collected on a number of known and potential risk factors for these tumors. The study has been conducted in 13 countries: Australia, Canada, Denmark, Finland, France, Germany, Israel, Italy, Japan, New Zealand, Norway, Sweden, and the UK using a common core protocol. Enrolled in the study have been 2,765 individuals with gliomas, 2,425 with meningiomas, 1,121 with acoustic neuromas, 109 with malignant parotid gland tumors and 7,658 controls. In addition to assessing brain cancer risk, particular attention has been paid to estimating the amount and direction of potential recall and participation biases and their impact upon study results. Results have been presented for countries individually with consistently no statistically-significant within-country association identified between phone use and brain cancer identified, as in Germany [160], [161], France [162], Sweden [163], and Japan [164]. One exception was in Israel, where the odds ratios (OR) for benign and malignant parotid gland tumors in the highest category of cumulative number of calls and call time without use of hand-free devices were 1.58 (95\% confidence interval: 1.11, 2.24) and 1.49 $(1.05,2.13)$, respectively [165].

When INTERPHONE data from multiple countries has been compiled, there has been a significantly increased risk of glioma $(\mathrm{OR}=1.40 ; 95 \% \mathrm{CI} 1.03-1.89)$, but only among those in the highest $10 \%$ of recalled cumulative call time (more than $1640 \mathrm{~h}$ ). Any increased risk was not statistically significant for meningiomas $(\mathrm{OR}=1.15 ; 0.81-1.62)$ [166]. One issue raised by the investigators was that there were implausible values of reported use in the highest user group. Odds ratios for glioma did tend to be greater in the temporal lobe than in other lobes of the brain, but the CIs around the lobe-specific estimates were wide. The ORs for glioma also tended to be greater in subjects who reported usual phone use on the same side of the head as their tumor than on the opposite side. In terms of actual exposure, represented by total cumulative specific energy (TCSE; J/kg), when 553 glioma and 676 meningioma cases of brain tumor from the Australian, Canadian, French, Israeli and New Zealand components of the Interphone Study, whose tumors were localised by neuroradiologists, were compared with controls matched for age, sex and region, and compared against 1762 and 1911 controls, 
respectively, ORs for glioma were below 1.0 within the first four quintiles of TCSE, but above 1.0 in the highest quintile, 1.35, approaching but not quite achieving statistical significance (95\% CI 0.96 to 1.90) [167]. In a complementary analysis in which 44 glioma and 135 meningioma cases in the most exposed area of the brain were compared against gliomas and meningiomas located elsewhere, increased ORs were noted for tumors in the most exposed part of the brain in those with 10 or more years of mobile phone use (OR 2.80, 95\% CI 1.13 to 6.94 for glioma). And, in pooled analysis across the four Nordic countries and the UK, increased risk of a tumor on the same side of the head as reported phone use that has persisted for $\geq 10$ years was noted $(\mathrm{OR}=1.8,95 \% \mathrm{CI}: 1.1-3.1)$ [168].

No increased risk of acoustic neuroma was identified in any study [169]. Overall, the INTERPHONE investigators concluded that there were no conclusive data linking cell-phone use and risk of brain malignancies, except after prolonged and exorbitant use. Criticisms have been made of the INTERPHONE studies, however, relating, among other issues, to recall and misclassification biases potentially exacerbated by low response rates [170]- [172].

In a meta-analysis drawing from both sets of studies (Hardell et al and INTERPHONE), Hardell et al found that the odds ratio for glioma (1.0; 95\% CI, 0.9-1.1) increased to 1.3 (1.1-1.6) after a 10-year latency period, with the highest risk identified for ipsilateral exposure ( $\mathrm{OR}=1.9$; 1.4-2.4) versus $\mathrm{OR}=1.2(0.9-1.7)$ with contralateral exposure [173]. The odds of acoustic neuroma (OR=1.0; 0.8-1.1) also increased after a 10-year latency period, but just failed to achieve statistical significance $(\mathrm{OR}=1.3 ; 0.97-1.9)$, except when ipsilateral exposure was considered alone (OR=1.6; 1.1-2.4). No consistent pattern of increased risk was uncovered for meningiomas. In terms of age, the highest risk of brain cancer was identified among those who were under 20 years of age at the time they first started using wireless phones.

Outside these two sources of multiple studies, another source of data stems from the previously-mentioned SEER database in the U.S., drawing from which Little et al compared epidemiological data from 12 registries (Atlanta, Detroit, Los Angeles, San Francisco, San JoseMonterey, Seattle, rural Georgia, Connecticut, Hawaii, Iowa, New Mexico, and Utah) against incidence trends reported by the INTERPHONE Study Group and Hardell's group in Sweden [174]. U.S. population-based data was evaluated for glioma incidence from 1992 to 2008, a period of time during which mobile phone use increased dramatically from virtually $0 \%$ to almost $100 \%$ of the U.S. population. During these years, 24,813 non-Hispanic Caucasians 18 years or older were diagnosed with glioma. Age-specific incidence rates of glioma remained generally stable from 1992 to 2008 (-0.02\% change per year, $95 \%$ confidence interval $-0.28 \%$ to $0.25 \%)$, despite the exponential increase in cell-phone use. The authors concluded that the decline in brain cancer rates they observed was inconsistent with the association between brain cancer and mobile phone use conjectured by Hardell's group, since rates should have been at least $40 \%$ higher than observed. On the other hand, they felt that the SEER data could be consistent with the glioma rates predicted based upon the small proportion of highly-exposed individuals reported in the INTERPHONE study.

Overall, results on the association between mobile phone use and brain cancer certainly might be considered suggestive, particularly in terms of long-term risk after years of exposure to cell phones, especially when used extensively. However, in two just-published reviews, Swerdlow 
et al [155] and Repacholi et al [11] both noted the inconclusiveness of current data, and on the limitations imposed by the absence of data both on exposures beyond 10 to 15 years, and on childhood cancers. Echoing Carpenter's concerns about EMF exposures in general [10], what is potentially alarming is the potential for further increases in brain cancer risk after latencies beyond ten years, especially given the now almost-universal use of cell phones and other handheld electronic devices by adolescents and children.

\subsection{Diet (maternal diet during pregnancy/childhood diet)}

Many of the same methodological issues and sources of potential bias (e.g., recall and ascertainment bias) pertain to maternal and childhood diet as to electromagnetic field exposure, rendering research to address the association between diet and childhood brain cancer difficult. For that reason, the research into this issue is, again, inconclusive. The most consistently positive association between diet and childhood brain cancer risk has been for cured meats, like hot dogs. In Denver, Colorado, cured and broiled meat consumption by mothers during pregnancy and by children themselves was assessed in 234 childhood cancer cases (including 45 brain tumor patients) and 206 controls selected by random digit dialing [175]. Five meat groups (ham, bacon, or sausage; hot dogs; hamburgers; bologna, pastrami, corned beef, salami, or lunch meat; charcoal-broiled foods) were assessed. Exposures among U.S. standard metropolitan statistical areas were compared, with adjustments made for confounders. Maternal hot dog consumption once or more weekly was statistically associated with childhood brain tumors $(\mathrm{OR}=2.3,95 \% \mathrm{CI}, 1.0-5.4)$. Meanwhile, among children, eating hamburgers once or more times per week was associated with a non-statistically increased risk of ALL $(\mathrm{OR}=2.0, \mathrm{CI}=0.9-4.6)$, as was eating hot dogs once or more times weekly with brain tumors $(2.1 ; 0.7-6.1)$. However, among children, the combination of no vitamins and eating cured meats was associated more strongly with both ALL and brain cancer than either no vitamins or meat consumption alone, producing ORs between 2 and 7, suggesting possible adverse effects of dietary nitrites and nitrosamines.

Bunin et al and the Children's Cancer Group conducted a case-control study specifically assessing the effects of maternal diet during pregnancy on the risk of childhood astrocytoma in 155 cases and 155 matched controls, all under age six, the controls selected by random-digit dialing [176]. A trend again was observed for consumption of cured meats (adjusted odds ratio [OR] for the highest versus lowest intake quartile $=1.7, \mathrm{p}=0.10$ ). Iron supplements were associated with a significant decrease in astrocytoma risk ( $\mathrm{OR}=0.5,95 \% \mathrm{CI}, 0.3-0.8)$. No significant trends were observed for nitrosamine $(\mathrm{OR}=0.8, \mathrm{p}=0.60)$; nitrites $(1.3, \mathrm{p}=0.54)$; nitrates $(0.7, \mathrm{p}=0.43)$; vitamin $\mathrm{C}(0.7, \mathrm{p}=0.37)$; or vitamin $\mathrm{E}(0.7, \mathrm{p}=0.48)$. Unfortunately, income level was a potential confounder.

In yet another high-profile case-control study, Bunin et al examined maternal diet relative to the risk of primitive neuroectodermal tumors (PNET) of the brain in offspring, with all 166 cases again under the age of six years at diagnosis [177]. As in the previously-mentioned study, controls were selected by random-digit dialing and matched for age and race. Telephone interviews with mothers included questions on the frequency of consumption of alcohol, vitamin and mineral supplements, and 53 specific foods during pregnancy. Significant 
protective trends were observed for vegetables (OR for the highest versus lowest quartile group for intake, $0.37 ; \mathrm{p}=0.005)$, fruits and fruit juices $(\mathrm{OR}=0.28 ; \mathrm{p}=0.003)$, vitamin $\mathrm{A}(0.59$; $\mathrm{p}=0.03)$, vitamin $\mathrm{C}(0.42 ; \mathrm{p}=0.009)$, nitrate $(0.44 ; \mathrm{p}=0.002)$, and folate $(0.38 ; \mathrm{p}=0.005)$. Taking iron $(0.43 ; \mathrm{p}=0.004)$, calcium $(0.42 ; \mathrm{p}=0.05)$, and vitamin $\mathrm{C}(0.35 ; \mathrm{p}=0.04)$ supplements at any time during pregnancy and multivitamins over the first six weeks $(0.56 ; \mathrm{p}=0.02)$ all were associated with decreased risk. On multivariate analyses, folate, early multivitamin use, and iron supplements remained protective [177]. A non-significant trend of increasing risk was observed for nitrosamine consumption $(1.65 ; \mathrm{p}=0.15)$.

Concerns over the consumption of nitrates, nitrites and nitroamines have been expressed by others, given the susceptibility of rats to develop brain tumors in response to N-nitroso urea exposure, the morphological similarity between these tumors and those observed in humans, and the presence of nitrate salts in many fertilizers [178]. Consistent with this potential risk, one meta-analysis of brain cancer risk in U.S. farmers yielded a relative risk of 1.30 (95\% CI, $1.09,1.56)[179]$, though pesticides, to which farmers also often are exposed, are another potential explanatory factor. In yet another case-control study, an increased risk of childhood astrocytomas was detected in association with in utero exposure to nitrites via a residential water source [180].

\subsection{Environmental neurocarcinogens and parental occupation}

As confusing and diverse the literature on EMF and diet is, it is even more so with respect to environmental and occupational exposures, due to the difficulties ascertaining and quantifying levels of exposure, especially when that exposure is second-hand to a child.

Pesticide exposure, both first-hand and second-hand, has been shown to be associated with increased brain cancer risk in children in a number of studies; but effects have tended to be modest and sometimes conflicting. Daniels et al [181] reviewed the results of 31 studies published between 1970 and 1996 and noted methodological issues in most of them, including small sample sizes, inadequate measurement of actual exposure, and potential biases related to the selection of controls. A further inconsistency was the lack of an effect of direct exposure to the child in studies in which an effect of parental occupational exposure was identified, a clearly counter-intuitive discovery [181]. Risks also varied with the type of pesticide and type and level of exposure. For example, Shim et al compared 526 brain cancer cases diagnosed before age 10 years and identified from statewide cancer registries of four U.S. Atlantic Coast states versus one-to-one-matched controls selected via random digit dialing [182]. Exposure risk was assessed through computer-assisted telephone interviews with mothers. Using information on residential pesticide use and jobs held by fathers over the 2-year period prior to the child's birth, potential exposures to insecticides, herbicides, and fungicides were estimated. For each occupation, two raters independently classified the probability and intensity of exposure. A significantly increased risk of astrocytoma was associated with exposures to herbicides from residential use ( $\mathrm{OR}=1.9 ; 95 \% \mathrm{CI}, 1.2-3.0)$. Combining parental exposures to herbicides from both residential and occupational sources, the elevated risk remained significant (1.8; 1.1-3.1). Little association was observed with primitive neuroectodermal tumors (PNET) for any of the pesticide classes or exposure sources considered. In 
another study, the risk of childhood brain cancer was again assessed relative to parental exposure to different classes of pesticide in 154 children diagnosed with astrocytoma and 158 children diagnosed with primitive neuroectodermal tumors (PNET) in the United States and Canada between 1986 and 1989 [183]. Controls again were selected by random digit dialing and were individually matched to cases by race, age, and geographic area. Each job in the fathers' work history and the usual occupation of mothers were assigned a probability, intensity, and frequency of exposure to insecticides, herbicides, and agricultural and nonagricultural fungicides. Elevated risks of astrocytoma were identified for paternal exposure (ever vs. never) to all four classes of pesticides (odds ratios $(\mathrm{OR})=1.4-1.6$ ), while an increased risk of PNET was observed only for herbicides $(\mathrm{OR}=1.5)$. For mothers, odds ratios for astrocytoma were elevated for insecticides, herbicides, and non-agricultural fungicides $(\mathrm{OR}=$ 1.3-1.6) but not agricultural fungicides $(\mathrm{OR}=1.0)$. Concerns have been raised about the accuracy of the levels of probability, intensity, and frequency of exposure assigned to mothers and fathers. Interestingly, both studies that assessed the use of no-pest strips within the home identified increased childhood brain cancer risk [184], [185]. In the study by Leiss et al, this effect was dose dependent, with the odds ratio of brain tumors equal to 1.5 (95\% CI, 0.9-2.4) when exposure was limited to just the last three months of pregnancy, versus 1.8 (1.2-2.9) when exposure was for the full two years prior to and throughout pregnancy [185]. One potential mechanism for direct pesticide-induced cancer risk is their conversion via nitrites in the stomach into potentially-carcinogenic N-nitroso compounds [186]; though how this might affect an unborn child is unclear.

Hair dyes are another environmental and occupational neurocarcinogen that has been shown to significantly increase brain cancer risk. In a population-based case-control study involving 112 white women in Nebraska newly diagnosed with glioma between July 1988 and June 1993, versus 215 controls, a 1.7-fold increased risk of glioma was observed among those who had ever used hair coloring products $(95 \% \mathrm{CI}=1.0-2.9)$ [187]. This risk increased to 2.4 among those who had used permanent hair coloring products (95\%CI, 1.3-4.5), and the risk of glioblastoma increased with duration of exposure, to 4.9 (95\% CI, 1.6-15.7) after 21 or more years of permanent hair color use. Higher risks also were observed with earlier age at first use. In another study, the risk of brain cancer among children born on or after 1980 to women who had personally used hair dyes over the five years prior to pregnancy was increased 11-fold, though the confidence limits were broad (95\%CI, 1.2-90) [188]. Childhood brain cancers also were associated with non-work-related maternal exposure to any beauty products $(\mathrm{OR}=2.6,95 \% \mathrm{CI}$, $1.2-5.9)$ and to hair sprays $(3.4 ; 1.0-11)$.

Choi et al identified a significant risk of childhood brain cancer before age 5 in women living within one mile of a facility releasing toxic release inventory (TRI) chemicals while pregnant [189]. In 2008, Clapp, Jacobs and Loechler published a detailed review of environmental and occupational causes of cancer, a 40-page manuscript with extensive tables that list all chemicals and other environmental exposures associated with a variety of cancers. For brain cancers, evidence of an association is considered strong only for ionizing radiation [180].

Occupational exposures have been assessed both for the mother and father, but especially the latter, in terms of child cancer risk [4]. Besides farming/agriculture, associations 
have been reported for the aircraft, electronics, petroleum, and pulp and paper industries, as well as for any industries associated with increased exposures to paints, solvents, other chemicals, pesticides, ionizing radiation, and electromagnetic fields [4], [190]. Albeit now more than 20 years old, Savitz and Chen wrote a very thorough paper summarizing all studies performed to date assessing the risk of childhood brain cancers, hematopoietic malignancies, and other malignancies relative to both paternal and maternal occupations [191]. Occupations were subdivided into motor vehicle related occupations, machinist and factory workers, occupations with paint exposure, occupations with chemical exposure, the petroleum industry, occupations with exposure to aggregated hydrocarbons, electronics, occupations associated with ionizing radiation, occupations with metal exposure, agriculture, construction, pulp and paper, aerospace and aircraft industries, and other occupations (printing workers, graphic arts workers, and glass, clay and stone industry). For virtually every occupational category, there was at least one study identifying a statistically increased odds ratio for childhood nervous system cancer. Table 2 summarizes that list, noting the number of studies in each job category, the number of studies with an odds ratio for childhood brain cancer $>1.0$, the number of studies with an odds ratio statistically greater than 1.0, and the range of odds ratios within that job category.

Note that, in no category for which there was more than a single study, was every odds ratio for childhood brain cancer statistically greater than one. Note also that the industries in which all odds ratios were $>1.0$, even if not statistically significant, were the petroleum industry, electrical work, metal work, and pulp and paper. Note also that some industries, like health care, were not mentioned. Among mothers, the odds ratios for childhood brain cancer were 3.3 for occupations with chemicals on the skin, 3.0 for occupations involving inhaled chemicals of fumes, 1.6 for bakers, and 4.0 for occupations requiring protective clothing or equipment [191]; only the last OR was statistically greater than 1.0.

In a later and also quite thorough review of the literature, published in 1998, Colt and Blair reviewed 48 papers published between 1974 and 1987, encompassing relative risk estimates for over 1000 specific cancer/occupation and cancer/exposure combinations [192]. Of these papers, 23 contained data assessing the relationship between paternal occupations and childhood nervous system cancers other than neuroblastoma; maternal occupations only were evaluated in terms of childhood leukemia risk. In table form, these authors listed studies by exposure, categorizing into electromagnetic fields; paints and pigments; hydrocarbons; metals; and motor vehicle-related occupations. These results are summarized in Table 3.

As in the review by Savitz and Chen, the results were conflicting, the authors themselves concluding that the evidence was strongest in support of an association between paternal exposure to paints and pigments [192]. Results on maternal occupations were scant and yielded no statistically significant associations.

More recently published studies yield much the same diffuse and inconsistent results [193][196], including one recently published study (2008) in Taiwan in which no associations among 


\begin{tabular}{|c|c|c|c|c|}
\hline Occupation/Main Exposure & Number of studies & $\begin{array}{c}\text { Number of OR "/> } \\
1.0\end{array}$ & $\begin{array}{c}\text { \# OR statistically "/> } \\
1.0\end{array}$ & Range of OR \\
\hline Motor vehicles & 7 & 3 & 1 & $0.6-2.8$ \\
\hline Machinist \& factory workers & 5 & 3 & 1 & $0.7-4.4$ \\
\hline Paint & 4 & 3 & 1 & $1.0-7.0$ \\
\hline Chemicals & 6 & 5 & 3 & $0.8-10.0$ \\
\hline Petroleum & 3 & 3 & 0 & $1.3-3.1$ \\
\hline Aggregated hydrocarbons & 6 & 4 & 1 & $0.5-3.2$ \\
\hline Electrical & 4 & 4 & 2 & $1.6-11.8$ \\
\hline Ionizing radiation & 6 & 5 & 2 & $1.0-2.2$ \\
\hline Metals & 3 & 3 & 1 & $1.6-2.7$ \\
\hline Agriculture & 4 & 2 & $\mathrm{n} / \mathrm{a}$ & $0.6-2.0$ \\
\hline Construction & 4 & 3 & 2 & $0.9-2.3$ \\
\hline Pulp \& paper & 3 & 3 & 1 & $1.6-4.0$ \\
\hline Aerospace \& aircraft & 3 & 2 & 1 & $1.0-\infty^{*}$ \\
\hline Printing workers & 1 & 1 & 1 & 4.5 \\
\hline Graphic arts & 1 & 1 & 1 & 21.9 \\
\hline Glass, clay, stone & 1 & 1 & 0 & 1.5 \\
\hline Total & 61 & 46 & 18 & $0.5-\infty *$ \\
\hline
\end{tabular}

Savitz and Chen, 1990 [1][9][1]

* $\infty=$ infinity

Table 2. Paternal Occupation and Childhood Nervous System Cancer Risk

202 young brain cancer cases, ages 0 to 29 years, were identified across a wide variety of occupations [197].

Finally, in one novel study, Rosso et al examined whether or not there was an association between a father's hobbies and brain cancer risk in their child, specifically looking at medulloblastomas and other PNET in 318 children under age 6 versus 318 randomly selected population controls [198]. On multivariate analyses, the only significant association was for lawn care with pesticides [during pregnancy: odds ratio $(\mathrm{OR})=1.6,95 \%$ confidence interval (CI): 1.0, 2.5; after birth: $\mathrm{OR}=1.8,95 \% \mathrm{CI}: 1.2,2.8]$.

\subsection{Other potential risk factors}

Numerous other risk factors for childhood brain cancer have been reported, albeit mostly in single studies. Neonatal head circumference was found to be associated with an increased risk 


\begin{tabular}{|c|c|c|c|c|}
\hline Main Exposures & \# RR estimates & Number of RR "/> 1.0 & \# RR statistically "/> 1.0 & Range of RR \\
\hline Electromagnetic fields & 55 & 45 & 9 & $0.3-73.3$ \\
\hline Paints \& pigments & 14 & 13 & 4 & $1.0-\infty$ \\
\hline Hydrocarbons & 28 & 12 & 2 & $0.4-4.0$ \\
\hline Metals & 17 & 15 & 4 & $0.8-5.3$ \\
\hline Motor vehicles, etc. & 32 & 12 & 2 & $0.1-5.9$ \\
\hline Total & 146 & 97 & 21 & $0.1-\infty$ \\
\hline \multicolumn{5}{|l|}{ Colt and Blair, 1998 [192] } \\
\hline${ }^{*} \infty=$ infinity & & & & \\
\hline
\end{tabular}

Table 3. Paternal Occupation and Childhood Nervous System Cancer Risk

of brain cancer by Samuelson et al, who analysed 1,010,366 individuals with 12,378,172 personyears of follow-up, from which 453 individuals ages 0 to 15 years were diagnosed with brain cancer [199]. In this population, the relative risk of brain cancer was 1.27 (95\%CI 1.16-1.38) for every $1 \mathrm{~cm}$ increase in head circumference, after adjusting for birth-weight, gestational age, and gender. In another study of 746 invasive CNS cancers in children less than 4 years old, after adjusting for parental education, elevated birth-weight was associated with an odds ratio of 1.71 for astrocytoma $(95 \% \mathrm{CI}, 1.01-2.90)$; but birth weight was not associated with an increased risk of PNET [42].

Prior malignancy has been associated with a variety of malignancies in the literature, including brain cancer. Some of this increased risk almost certainly is secondary to radiation therapy to the head and neck [129]. Yet even when head irradiation is not utilized, brain cancer risk may be increased. Maule et al identified a total of 133 second malignant neoplasms in 16,540 patients with hematopoietic malignancies (12,731 leukemias, 1246 Hodgkin's lymphomas, and 2563 non-Hodgkin's lymphomas) after an average follow-up of 6.5 years [200]. The most frequent second malignancies after leukemia were brain cancer (standardized incidence ratio [SIR] = 8.52; $95 \% \mathrm{CI}=5.13$ to 13.3 ), non-Hodgkin's lymphoma ( $\mathrm{SIR}=9.41 ; 4.30$ to 17.9 ), and thyroid cancer ( $\mathrm{SIR}=18.8 ; 8.60$ to 35.7). The most frequent after non-Hodgkin's lymphoma were thyroid cancer ( $\mathrm{SIR}=40.4 ; 14.8$ to 88.0 ) and brain cancer (SIR $=6.97 ; 1.90$ to 17.9$)$. There was no increased incidence of brain cancer following Hodgkin's lymphoma.

In Rio de Janeiro, in a hospital-based case-control study involving 231 adults with primary brain tumors and 261 controls matched for gender and age among in-patients hospitalized for various conditions unrelated to brain cancer, past head injury was found to be significantly more frequent among cases $(46 \%)$ than controls $(36 \%)(\mathrm{OR}$ (adjusted) $=1.49 ; 95 \% \mathrm{CI}=1.03-2.15)$ [201]. Moreover, a dose-response effect was observed related to the number of head injuries, and a statistically-borderline association was observed specifically for meningioma (OR(adj) $=1.63 ; 0.96-2.75$ ). These results have not yet been replicated and, to date, no such association has been identified for childhood brain cancer. 
In a nationwide Danish study on the occurrence of cancer among 8,093 Danish individuals born with an oral cleft deformity between 1936 and 1998 and followed in the Danish Cancer Registry from 1968 through 1998, a total of 175,863 person-years, the possible association between cancer and oral clefts was assessed [202]. The expected overall number of all cancers was 131, but 140 incident cancers were found, corresponding to a standardized incidence ratio of 1.07 ( $95 \% \mathrm{CI}, 0.90-1.26)$. Analyses of the 52 sites for all oral cleft cases and analyses stratified into three cleft subgroups and two sexes revealed only a few significant associations, one of which was the increased incidence of primary brain cancer among females, but not males, born with a cleft palate $(\mathrm{SIR}=3.11 ; 1.14,6.78)$.

Finally, medications are often listed as a potential risk factor for brain cancer [203], but there are almost no data scientifically supporting such a claim. In one case-control study of 163 matched pairs, patients under 15 years of age when diagnosed with astrocytoma between 1980 and 1986 were identified through the tumor registries of eight hospitals in Pennsylvania, New Jersey, and Delaware [204]. Controls were selected by random digit dialing, and matched to cases for age, race, and telephone area code and exchange. In this population, maternal antinausea medications significantly increased the risk of childhood astrocytoma $[\mathrm{OR}=2.0, \mathrm{p}=$ $0.04]$, while gestational exposure to marijuana was of borderline significance $(\mathrm{OR}=2.8, \mathrm{p}=$ 0.07). Gestational exposures to neurally-active medications, alcohol, and tobacco did not increase brain cancer risk, consistent with other studies [203]. The association between antiemetics and increased brain cancer risk was not identified in another, Swedish study in which this was assessed [205]. In the Swedish study, no significant changes in risk were noted after exposure to iron supplementation, anti-emetics, analgesics, antibiotics or any other drug, with the exception that 10 children with a brain tumor had been exposed to some beta-blocking agent in utero versus just two children without brain tumor (adjusted OR 5.3, 95\%CI 1.2-24.8). In addition, a tendency towards a protective effect was observed for prenatal exposure to folic acid (adjusted OR 0.6; 0.3-1.1). Finally, case-control data from M. D. Anderson Cancer Center and the University of California, San Francisco were pooled to conduct an analysis stratified by histological subtype of glioma to identify any potentiating effects of inflammation-related variables and antihistamine use [206]. An association was discovered between long-term antihistamine use and the increased risk of anaplastic gliomas, especially when the length of use was considered in conjunction with a history of asthma or allergy: anaplastic cases with no history of asthma or allergy were 2.94 times more likely than controls to report antihistamine use lasting 10 years or more; while anaplastic cases with a history of asthma or allergy were 2.34 times more likely. Conversely, anti-inflammatory medication use was protective against glioblastoma ( $\mathrm{OR}=0.80 ; 95 \% \mathrm{CI}: 0.65,0.99)$, especially among individuals with no history of asthma or allergies. No statistically-significant effects of anti-inflammatory drugs or antihistamines were evident for other histological subtypes of glioma.

\section{Summary, clinical applications, and directions for future research}

Brain cancer is one of the most fear-provoking and lethal of all illnesses, two reasons that concerns about the potential for increased rates from the use of hand-held electronic devices 
have been raised. To date, however, there is no evidence that brain cancer incidence rates have increased at all over the same time period that the use of these devices has escalated exponentially. In the U.S. and U.K., where data are available, brain cancer incidence rates appear to be stable or declining. Mortality rates also are declining. That being said, there are virtually no readily-accessible data outside the U.S. and the U.K., and there is some research evidence that any effects of such devices on brain cancer risk only become significantly and clinically manifest after years, if not decades of their use. Consequently, it may be too soon to have detected adverse effects and, if present, to determine the magnitude of such effects on brain cancer numbers.

Known risk factors for brain cancer are male gender, younger age among pediatric populations, and Caucasian race. A family or personal history of cancer, and in particular brain cancer appears to increase risk as well, as do radiation treatments to the head and neck area. In addition, a small percentage of brain cancer cases, likely 5 percent or less, occur within the context of a familial syndrome, the most common of which are neurofibromatosis and tuberous sclerosis. In such patients, the risk is high for a variety of intracranial and extra-cranial malignancies, so that continuous vigilance by qualified health care practitioners is paramount.

Unfortunately, research into a variety of suspected brain cancer risk factors has been fraught with difficulties, given problems accurately evaluating levels of exposure, controlling for numerous other potentially carcinogenic exposures, and issues like recall and ascertainment bias. As stated earlier, understanding about the true risk of hand-held devices like cell phones may not come until they have been in widespread use for several more years, at which point it may be too late to prevent whatever initial rise in cases results. The same is true for electromagnetic fields from the increasing number of household appliances, especially home computers that are entering our homes, though the trend has been towards negative-result studies as methodologies have advanced over the years. As for dietary factors, other than promoting good diet and moderation in the consumption of cured meats, little more can be said at this time. And all patients should be advised to exercise caution when partaking in any occupation, hobby or other activity that places one in regular close contact with chemicals or ionizing radiation.

Further research clearly is needed to clarify the huge number of yet-unanswered questions, but this must start with close and international monitoring of brain cancer rates, both overall and cancer-type specific. In the U.S., the SEER database is a huge advantage; but investigators need to utilize this database more and publish these results within the medical literature. The number and completeness of similar databases in other countries this author cannot say; but again, such databases need to be used for research purposes and resultant findings published on a regular basis, if changing trends in brain cancer incidence are to be detected early. As for establishing the magnitude of risk from devices like cell phones, if such risk actually exists, what are needed are large, prospective, longitudinal studies assessing dose-dependent effects, since it makes sense that the highest-volume users will be the ones most likely to present earliest with problems, a contention that already-published results support. Moreover, using prospective studies will largely counter the problems with recall and ascertainment bias that has plagued the numerous case-control studies published to date though, admittedly, such 
studies invariably must be larger and, hence costlier. This being said, it is important to recall those databases already in existence, like the SEER database and State and provincial cancer registries. Linking prospectively-acquired, multicenter exposure data with some database like these would provide a powerful research tool in the fight against brain cancer.

\section{Author details}

Adrianna Ranger

University of Western Ontario, London, Ontario, Canada

\section{References}

[1] Centers for Disease Control and Prevention (CDC)Trends in childhood cancer mortality--United States, (1990). MMWR Morb Mortal Wkly Rep 2007; , 56(48), 1257-1261.

[2] Linet, M. S, Ries, L. A, Smith, M. A, Tarone, R. E, \& Devesa, S. S. Cancer surveillance series: recent trends in childhood cancer incidence and mortality in the United States. J Natl Cancer Inst (1999). , 91(12), 1051-1058.

[3] Bunin, G. R, Feuer, E. J, Witman, P. A, \& Meadows, A. T. Increasing incidence of childhood cancer: report of 20 years experience from the greater Delaware Valley Pediatric Tumor Registry. Paediatr Perinat Epidemiol (1996). , 10(3), 319-338.

[4] Gurney, J. G, Smith, M. A, \& Bunin, G. R. CNS and miscellaneous intra-cranial and intraspinal neoplasms. SEER Pediatric Monograph, National Cancer Institute, (2001). Ref Type: Serial (Book,Monograph), 51-63.

[5] National Cancer InstituteA Snapshot of Pediatric Cancers: Incidence on Mortality Rate Trends. (2011). Ref Type: Report

[6] Ellison, L. F. De P, Mery LS, Grundy PE, Canadian Cancer Society's Steering Committee for Canadian Cancer Statistics. Canadian cancer statistics at a glance: cancer in children. CMAJ (2009). Feb 17; 180(4), 422-4.

[7] Rendón-macías, M. E, Ramos-becerril, C, Bernardez-zapata, I, \& Iglesias-leboreiro, J. Cancer epidemiology in children and adolescents at private health care ((1995). Article in Spanish]. Rev Med Inst Mex Seguro Soc 2008; , 46(4), 353-360.

[8] Brain Tumor FactsAmerican Brain Tumor Association. (2012). Ref Type: Electronic Citation 
[9] Chatenoud, L, Bertuccio, P, Bosetti, C, Levi, F, \& Negri, E. La Vecchia C. Childhood cancer mortality in America, Asia, and Oceania, 1970 through 2007. Cancer (2010). , 116(21), 5063-5074.

[10] Carpenter, D. O. Electromagnetic fields and cancer: the cost of doing nothing. Rev Environ Health (2010). , 25(1), 75-80.

[11] Repacholi, M. H, Lerchl, A, Roosli, M, et al. Systematic review of wireless phone use and brain cancer and other head tumors. Bioelectromagnetics (2012). , 33(3), 187-206.

[12] Vrijheid, M, Deltour, I, Krewski, D, Sanchez, M, \& Cardis, E. The effects of recall errors and of selection bias in epidemiologic studies of mobile phone use and cancer risk. J Expo Sci Environ Epidemiol (2006). , 16(4), 371-384.

[13] Deorah, S, Lynch, C. F, Sibenaller, Z. A, \& Ryken, T. C. Trends in brain cancer incidence and survival in the United States: Surveillance, Epidemiology, and End Results Program, 1973 to 2001. Neurosurg Focus (2006). E1.

[14] Vutuc, C, Waldoer, T, \& Haidinger, G. Cancer mortality in Austria: Wien Klin Wochenschr (2004). , 1970-2002.

[15] Fang, Z, Kulldorff, M, \& Gregorio, D. I. Brain cancer mortality in the United States, 1986 to 1995: a geographic analysis. Neuro Oncol (2004). , 6(3), 179-187.

[16] Monteiro, G. T, \& Koifman, S. Brain tumors mortality in Brazil, 1980-1998]. [Article in Portuguese]. Cad Saude Publica (2003). , 19(4), 1139-1151.

[17] Johannesen, T. B, Angell-andersen, E, Tretli, S, Langmark, F, \& Lote, K. Trends in incidence of brain and central nervous system tumors in Norway, 1970-1999. Neuroepidemiology (2004). , 23(3), 101-119.

[18] De Vocht, F, Burstyn, I, \& Cherrie, J. W. Time trends (1998-2007) in brain cancer incidence rates in relation to mobile phone use in England. Bioelectromagnetics (2011). , 32(5), 334-349.

[19] Yeole, B. B. Trends in the brain cancer incidence in India. Asian Pac J Cancer Prev (2008). , 9(2), 267-270.

[20] Smith, M. A, Freidlin, B, Ries, L. A, \& Simon, S. L. Trends in reported incidence of primary malignant brain tumors in children in the United States. J Natl Cancer Inst (1998). , 90(17), 1269-1277.

[21] Mcnally, R. J, Kelsey, A. M, Cairns, D. P, Taylor, G. M, Eden, O. B, \& Birch, J. M. Temporal increases in the incidence of childhood solid tumors seen in Northwest England (1954-1998) are likely to be real. Cancer 92 [7], (2001). Ref Type: Electronic Citation, 1967-1976.

[22] The SEER databaseNational Cancer Institute. (2012). Ref Type: Electronic Citation 
[23] Brain Cancer Fact Sheet: The SEER databaseNational Cancer Institute. (2012). Ref Type: Electronic Citation

[24] Age-adjusted SEER Incidence Rates by YearRace and Sex- Cancer of the Brain and Other Nervous System (Invasive). National Cancer Institute. (2012). Ref Type: Electronic Citation

[25] Age-adjusted Incidence and Mortality Rates: The SEER databaseNational Cancer Institute. (2012). Ref Type: Electronic Citation

[26] Mao, Y, Desmeules, M, Semenciw, R. M, Hill, G, Gaudette, L, \& Wigle, D. T. Increasing brain cancer rates in Canada. CMAJ (1991). , 145(12), 1583-1591.

[27] Preston-martin, S, Lewis, S, Winkelmann, R, Borman, B, Auld, J, \& Pearce, N. Descriptive epidemiology of primary cancer of the brain, cranial nerves, and cranial meninges in New Zealand, Cancer Causes Control 4 [6], 529-538. (1993). Ref Type: Electronic Citation, 1948-88.

[28] Legler, J. M, Ries, L. A, Smith, M. A, et al. Cancer surveillance series [corrected]: brain and other central nervous system cancers: recent trends in incidence and mortality. J Natl Cancer Inst (1999). , 91(16), 1382-1390.

[29] Grovas, A, Fremgen, A, Rauck, A, et al. The National Cancer Data Base report on patterns of childhood cancers in the United States. Cancer (1997). , 80(12), 2321-2332.

[30] Khatua, S, Sadighi, Z. S, Pearlman, M. L, Bochare, S, \& Vats, T. S. Brain Tumors in Children- Current Therapies and Newer Directions. Indian J Pediatr (2012). Feb 1 [Epub ahead of print] 2012.

[31] Khalatbari, M. R, Hamidi, M, \& Moharamzad, Y. Glioblastoma multiforme with very rapid growth and long-term survival in children: report of two cases and review of the literature. Childs Nerv Syst (2011). , 27(8), 1347-1352.

[32] MacDonadl TJAguilera D, Kramm CM. Treatment of high-grade glioma in children and adolescents. Neuro Oncol (2011). , 13(10), 1049-1058.

[33] Sievert, A. J, \& Fisher, M. J. Pediatric low-grade gliomas. J Child Neurol (2009). , 24(11), 1397-1408.

[34] Qaddoumi, I, Sultan, I, \& Gajjar, A. Outcome and prognostic features in pediatric gliomas: a review of 6212 cases from the Surveillance, Epidemiology, and End Results database. Cancer (2009). , 115(24), 5761-5770.

[35] Taylor, M. D, Sanford, R. A, \& Boop, F. A. Cerebellar pilocytic astrocytomas. In: Albright AL, Pollack IF, Adelson PD, editors. Principles and Practice of Pediatric Neurosurgery. New York: Thieme Medical pUBLISHERS, iNC.; , 655-667.

[36] Epstein, F, \& Mccleary, E. L. Intrinsic brain-stem tumors of childhood: surgical indications. J Neurosurg (1986). , 64(1), 11-15. 
[37] Khatua, S, Moore, K. R, Vats, T. S, \& Kestle, J. R. Diffuse intrinsic pontine glioma-current status and future strategies. Childs Nerv Syst (2011). , 27(9), 1391-1397.

[38] Farmer, J-P, Mcneely, P. D, \& Freeman, C. R. Brainstem Gliomas. In: Albright AL, Pollack IF, Adelson PD, editors. Principles and Practice of Pediatric Neurosurgery. New York: Thieme Medical Publishers, Inc.; , 640-654.

[39] Diller, L, Chow, E. J, Gurney, J. G, et al. Chronic disease in the Childhood Cancer Survivor Study cohort: a review of published findings. J Clin Oncol (2009). , 27(14), 2339-2355.

[40] Davis, D. L, Ahlbom, A, Hoel, D, \& Percy, C. Is brain cancer mortality increasing in industrial countries? Am J Ind Med (1991). , 19(4), 421-431.

[41] Tseng, J. H, \& Tseng, M. Y. Survival analysis of children with primary malignant brain tumors in England and Wales: a population-based study. Pediatr Neurosurg. 42 [2], (2006). Ref Type: Electronic Citation, 67-73.

[42] Von Behren, J, \& Reynolds, P. Birth characteristics and brain cancers in young children. Int J Epidemiol. 32 [2], (2003). Ref Type: Electronic Citation, 248-256.

[43] Gajjar, A, Sanford, R. A, Heideman, R, et al. Low-grade astrocytoma: a decade of experience at St. Jude Children's Research Hospital. J Clin Oncol. 15 [8], (1997). ef Type: Electronic Citation, 2792-2799.

[44] Pollack, I. F, Gerszten, P. C, Martinez, A. J, et al. Intracranial ependymomas of childhood: long-term outcome and prognostic factors. Neurosurgery 37 [4], (1995). Ref Type: Electronic Citation, 655-666.

[45] Darefsky, A. S, \& Dubrow, R. International variation in the incidence of adult primary malignant neoplasms of the brain and central nervous system. Cancer Causes Control (2009). , 20(9), 1593-1604.

[46] Bunin, G. Racial patterns of childhood brain cancer by histologic type. J Natl Cancer Inst (1987). , 78(5), 875-880.

[47] Farwell, J, \& Flannery, J. T. Cancer in relatives of children with central-nervous-system neoplasms. N Engl J Med. 311 [12], (1984). Ref Type: Electronic Citation, 749-753.

[48] Hemminki, K, Li, X, \& Collins, V. P. Parental cancer as a risk factor for brain tumors (Sweden). Cancer Causes Control 12 [3], (2001). Ref Type: Electronic Citation, 195-199.

[49] Hill, D. A, Inskip, P. D, Shapiro, W. R, et al. Cancer in first-degree relatives and risk of glioma in adults. Cancer Epidemiol Biomarkers Prev (2003). , 12(12), 1443-1448.

[50] Hill, D. A, Linet, M. S, Black, P. M, et al. Meningioma and schwannoma risk in adults in relation to family history of cancer. Neuro Oncol.2004 Oct;(2004). Ref Type: Electronic Citation, 6(4), 274-80. 
[51] Blumenthal, D. T, \& Cannon-albright, L. A. Familiality in brain tumors. Neurology (2008). , 71(13), 1015-1020.

[52] Ostrom, Q. T, Mcculloh, C, Chen, Y, et al. Family history of cancer in benign brain tumor subtypes versus gliomas. Front Oncol.2012;2:19.Epub 2012 Feb 28. (2012). Ref Type: Electronic Citation

[53] Kuitjen, R. R, \& Bunin, G. R. Risk factors for childhood brain tumors. Cancer Epidemiol Biomarkers Prev. 2 [3], (1993). Ref Type: Electronic Citation, 277-288.

[54] Kuitjen, R. R, Strom, S. S, Rorke, L. B, et al. Family history of cancer and seizures in young children with brain tumors: a report from the Childrens Cancer Group (United States and Canada). Cancer Causes Control. 4 [5], (1993). Ref Type: Electronic Citation, 455-464.

[55] Wrensch, M, Lee, M, Miike, R, et al. Familial and personal medical history of cancer and nervous system conditions among adults with glioma and controls. Am J Epidemiol. 145 [7], (1997). Ref Type: Electronic Citation, 581-593.

[56] Korf, B. R. The phakomatoses. Clin Dermatol (2005). , 23(1), 78-84.

[57] Van Der Hoeve, J. Eye symptoms in tuberous sclerosis of the brain. Trans Ophthalmol Soc UK (1920). , 40, 329-334.

[58] Alaraj, A. M, Valyi-nagy, T, \& Roitberg, B. Double phakomatosis; neurofibromatosis type-1 and tuberous sclerosis. Acta Neurochir (Wien) (2007). , 149(5), 505-509.

[59] Ferner, R. E. Neurofibromatosis 1 and neurofibromatosis 2: a twenty first century perspective. Lancet Neurol (2007). , 6(4), 340-351.

[60] Crump, T. Translation of case reports in Ueber die multiplen Fibrome der Haut und ihre Beziehung zu den multiplen Neuromen by F. v. Recklinghausen. Adv Neurol (1981). , 29, 259-275.

[61] Pearce JMSHistorical Note: Neurofibromatosis. J Neurol Neurosurg Psychiatry (2003).

[62] Lu-emerson, C, \& Plotkin, S. R. The Neurofibromatoses. Part 1: NF1. Rev Neurol Dis (2009). EE53., 47.

[63] Lu-emerson, C, \& Plotkin, S. R. The neurofibromatoses. Part 2: NF2 and schwannomatosis. Rev Neurol Dis (2009). EE86., 81.

[64] Evans, D. G, Howard, E, Giblin, C, et al. Birth incidence and prevalence of tumour prone syndromes: estimates from a UK genetic family register service. Am J Med Genet (2010). A:, 327-332.

[65] Ferner, R. E, Huson, S. M, Thomas, N, et al. Guidelines for the diagnosis and management of individuals with neurofibromatosis 1. J Med Genet (2007). , 44(2), 81-8. 
[66] Legendre, C. M, Charpentier-cote, C, Drouin, R, \& Bouffard, C. Neurofibromatosis type 1 and the "elephant man's" disease: the confusion persists: an ethnographic study. PLoS One (2011). e16409.

[67] Ferner, R. E. The neurofibromatoses. Pract Neurol (2010). , 10(2), 82-93.

[68] Hersh, J. H. American Academy of Pediatrics Committee on Genetics. Health supervision for children with neurofibromatosis. Pediatrics (2008). , 121(3), 633-642.

[69] Dodge, H. W, Lowe, J. G, Craig, W. M, et al. Gliomas of the optic nerves. Arch Neurol Psychiatr (1958). , 79, 607-621.

[70] Hottinger, A. F, \& Khakoo, Y. Neuro-oncology of Neurofibromatosis Type 1. Curr Treat Options Neurol (2009). , 11(4), 306-314.

[71] Leonard, J. R, Perry, A, Rubin, J. B, et al. The role of surgical biopsy in the diagnosis of glioma in individuals with neurofibromatosis-1. Neurology (2006). , 67(8), 1509-1512.

[72] Evans, D. G. Neurofibromatosis type 2: genetic and clinical features. Ear Nose Throat J (1999). , 78(2), 97-100.

[73] Fontaine, B, Sanson, M, Delattre, O, et al. Parental origin of chromosome 22 loss in sporadic and NF2 neuromas. Genomics (1991). , 10(1), 280-283.

[74] Fontaine, B, Hanson, M. P, Vonsattel, J. P, et al. Loss of chromosome 22 alleles in human sporadic spinal schwannomas. Ann Neurol (1991). , 29(2), 183-186.

[75] Jacoby, L. B. MacCollin M, Parry DM, et al. Allelic expression of the NF2 gene in neurofibromatosis 2 and schwannomatosis. Neurogenetics (1999). , 2(2), 101-108.

[76] Neurofibromatosis Conference StatementNational Institutes of Health. Consensus Development Conference. Arch Neurol (1988). , 45(5), 575-578.

[77] Gutmann, D. H, Aylsworth, A, Carey, J. C, et al. The diagnostic evaluation and multidisciplinary management of neurofibromatosis 1 and neurofibromatosis 2. JAMA (1997). , 278(1), 51-57.

[78] Osborne, J. P, Fryer, A, \& Webb, D. Epidemiology of tuberous sclerosis. Ann NY Acad Sci (1991). , 615, 125-127.

[79] Hong, C. H, Darling, T. N, \& Lee, C. H. Prevalence of tuberous sclerosis complex in Taiwan: a national population-based study. Neuroepidemiology (2009). , 33(4), 335-341.

[80] Morrison, P. J. Tuberous sclerosis: epidemiology, genetics and progress towards treatment. Neuroepidemiology (2009).

[81] Orlova, K. A, \& Crino, P. B. The tuberous sclerosis complex. Ann N Y Acad Sci (2010). Jan):, 87-105. 
[82] Grajkowska, W, Kotulska, K, Jurkiewicz, E, \& Matyja, E. Brain lesions in tuberous sclerosis complex. Review. Folia Neuropathol (2010). , 48(3), 139-149.

[83] Goh, S, Butler, W, \& Thiele, E. A. Subependymal giant cell tumors in tuberous sclerosis complex. Neurology (2004). , 63(8), 1457-1461.

[84] Hottinger, A. F, \& Khakoo, Y. Neurooncology of familial cancer syndromes. J Child Neurol (2009). , 24(12), 1526-1535.

[85] Seizinger, B. R, Rouleau, G. A, Ozelius, L. J, et al. Von Hippel-Lindau disease maps to the region of chromosome 3 associated with renal cell carcinoma. Nature (1988). , 332(6161), 268-269.

[86] Glasker, S. Central nervous system manifestations in VHL: genetics, pathology and clinical phenotypic features. Fam Cancer (2005). , 4(1), 37-42.

[87] Hassard, A. D, Boudreau, S. F, \& Cron, C. C. Adenoma of the endolymphatic sac. J Otolaryngol (1984). , 13, 213-216.

[88] Butman, J. A, Linehan, W. M, \& Lonser, R. R. Neurologic manifestations of von Hippel-Lindau disease. JAMA (2008). , 300(11), 1334-1342.

[89] Richard, S, Campello, C, Taillandier, L, Parker, F, \& Resche, F. Haemangioblastoma of the central nervous system in von Hippel-Lindau disease. French VHL Study Group. J Intern Med (1998). , 243(6), 547-553.

[90] Wanebo, J. E, Lonser, R. R, Glenn, G. M, \& Oldfield, E. H. The natural history of hemangioblastomas of the central nervous system in patients with von Hippel-Lindau disease. J Neurosurg (2003). , 98(1), 82-94.

[91] Thayer, S. P. di Magliano MP, Heiser PWeal. Hedgehog is an early and late mediator of pancreatic cancer tumorigenesis. Nature (2003). , 425(6960), 851-856.

[92] Shanley, S, Ratcliffe, J, Hockey, A, et al. Nevoid basal cell carcinoma syndrome: review of 118 affected individuals. Am J MedGenet (1994). , 50(3), 282-290.

[93] Kleihues, P, \& Schauble, B. zur Hausen A, Esteve J, Ohgaki H. Tumors associated with germline mutations: a synopsis of 91 families. Am J Pathol (1997). , 53.

[94] Li, F. P. Fraumeni JFJ, Mulvihill JJ, et al. A cancer family syndrome in twenty-four kindreds. Cancer Res (1988). , 48(18), 5358-5362.

[95] Birch, J. M. Li-Fraumeni syndrome. Eur J Cancer (1994). A(13):1935-1941.

[96] Evans, D. G, Wu, C. L, \& Birch, J. M. BRCA2: a cause of Li-Fraumeni-like syndrome. J Med Genet (2008). , 45, 62-63.

[97] Taylor, M. D, Mainprize, T. G, \& Rutka, J. T. Molecular insight into medulloblastoma and central nervous system primitive neuroectodermal tumor biology from hereditary syndromes: a review. Neurosurgery (2000). , 47(4), 888-901. 
[98] Foulkes, W. D. A tale of four syndromes: familial adenomatous polyposis, Gardner syndrome, attenuated APC and Turcot syndrome. QJM (1995). , 88(12), 853-863.

[99] Hamilton, S. R, Liu, B, Parsons, R. E, et al. The molecular basis of Turcot's syndrome. N Engl J Med (1995). , 332(13), 839-847.

[100] Paraf, F, Jothy, S, \& Van Meir, E. G. Brain tumor-polyposis syndrome: two genetic diseases? J Clin Oncol (1997). , 15(7), 2744-2758.

[101] Mclaughlin, M. R, Gollin, S. M, Lese, C. M, \& Albright, A. L. Medulloblastoma and glioblastoma multiforme in a patient with Turcot syndrome: a case report. Surg Neurol (1998). , 49(3), 295-301.

[102] Jamjoom, Z. A, Sadiq, S, Mofti, A. B, Al-mofleh, I, \& Ajarim, D. Turcot syndrome: report of a case and review of the literature. Int Surg (1989). , 74(1), 45-50.

[103] Schroder, S, Moehrs, D, Von Weltzien, J, Winkler, R, \& Otto, H. F. The Turcot syndrome. Report of an additional case and review of the literature. Dis Colon Rectum (1983). , 26(8), 533-538.

[104] Taylor, M. D, Mainprize, T. G, Rutka, J. T, Becker, L, Bayani, J, \& Drake, J. M. Medulloblastoma in a child with Rubenstein-Taybi Syndrome: case report and review of the literature. Pediatr Neurosurg (2001). , 35(5), 235-238.

[105] Burton, B. J, Kumar, V. G, \& Bradford, R. Granular cell tumour of the spinal cord in a patient with Rubenstein-Taybi syndrome. Br J Neurosurg (1997). , 11(3), 257-259.

[106] Enchondromatosis: In The Free Dictionary by Farlex at http://medical-dictionarythefreedictionary.com/enchondromatosis. (2008).

[107] Baumgart, R, Bürklein, D, Hinterwimmer, S, Thaller, P, \& Mutschler, W. The management of leg-length discrepancy in Ollier's disease with a fully implantable lengthening nail. J Bone Joint Surg Br (2005). , 87(7), 1000-1004.

[108] Shapiro, F. Ollier's Disease. An assessment of angular deformity, shortening, and pathological fracture in twenty-one patients. J Bone Joint Surg Am 1982 Jan;(1982). , 64(1), 95-103.

[109] Ranger, A, Szymczak, A, Hammond, R, \& Zelcer, S. Pediatric thalamic glioblastoma associated with Ollier's disease (multiple enchondromatosis): a rare case of concurrence. J Neurosurg Pediatr (2009). , 4(4), 363-367.

[110] Schwartz, H. S, Zimmerman, N. B, Simon, M. A, Wroble, R. R, Millar, E. A, \& Bonfiglio, M. The malignant potential of enchondromatosis. J Bone Joint Surg Am (1987). , 69(2), 269-274.

[111] Balcer, L. J, Galetta, S. L, Cornblath, W. T, \& Liu, G. T. Neuro-ophthalmologic manifestations of Maffucci's syndrome and Ollier's disease. J Neuroophthalmol (1999). , 19(1), 62-66. 
[112] Silve, C, \& Jüppner, H. Ollier disease. Orphanet J Rare Dis (2006). Sep 22;1:37 2006; $1: 37$.

[113] Boinet, E. Enchondrose rachitiforme. Arch Gen de Med (1904). , 194, 2689-2717.

[114] Ranger, A, Szymczak, A, Hammond, R, \& Zelcer, S. Do intracranial neoplasms differ in Ollier's disease and Maffucci's syndrome?- An in-depth analysis of the literature. [in press]. Neurosurgery (2009).

[115] Ranger, A, \& Szymczak, A. The association between intracranial tumours and multiple dyschondroplasia (Ollier's disease or Maffucci's syndrome): do children and adults differ? J Neurooncol (2009). , 95(2), 165-173.

[116] Altay, M, Bayrakci, K, Yildiz, Y, Erekul, S, \& Saglik, Y. Secondary chondrosarcoma in cartilage bone tumors: report of 32 patients. J Orthop Sci (2007). , 12(5), 415-423.

[117] Ozisik, Y, Meloni, A. M, Spanier, S. S, Bush, C. H, Kingsley, K. L, \& Sandberg, A. A. Deletion $1 \mathrm{p}$ in a low-grade chondrosarcoma in a patient with Ollier disease. Canc Genet Cytogen (1998). , 105(2), 128-133.

[118] Bovee JVMGGraadt van Roggen JF, Cleton-Jansen AM, Taminiau AHM, Woude HJ, van der Hogendoorn PCW. Malignant progression in multiple enchondromatosis (Ollier"s disease): An autopsy-based molecular genetic study. Human Pathol (2000). , 31(10), 1299-1303.

[119] Chang, S, \& Prados, M. D. Identical twins with Ollier's disease and intracranial gliomas: case report. Neurosurg (1994). , 34(5), 903-906.

[120] Robinson, D, Tieder, M, Halperin, N, Burshtein, D, \& Nevo, Z. Maffucci's syndrome--the result of neural abnormalities? Evidence of mitogenic neurotransmitters present in enchondromas and soft tissue hemangiomas. Cancer (1994). , 74(3), 949-957.

[121] Mann, I, Yates, P. C, \& Ainslie, J. P. Unusual case of double primary orbital tumour. Br J Ophthalmol. 37 [12], (1953). Ref Type: Electronic Citation, 758-762.

[122] Giles, D, Hewitt, D, Stewart, A, \& Webb, J. Malignant disease in childhood and diagnostic irradiation in utero. Lancet 271 [6940], 447. (1956). Ref Type: Electronic Citation

[123] Stewart, A, Webb, J, \& Hewitt, D. A survey of childhood malignancies. Br Med J. 1 [5086], (1958). Ref Type: Electronic Citation, 1495-1508.

[124] MacMahon BPrenatal x-ray exposure and childhood cancer. J Natl Cancer Inst. 28 [5], (1962). Ref Type: Electronic Citation, 1173-1191.

[125] Chowdhary, A, Spence, M. A, Sales, L, Rostomily, R. C, Rockhill, J. K, \& Silbergeld, D. L. Radiation associated tumors following therapeutic cranial radiation. Surg Neurol Int.2012;3:48.Epub 2012 May 14. (2012). Ref Type: Electronic Citation 
[126] Ron, E, Modan, B, et al. Tumors of the brain and nervous system after radiotherapy in childhood. N Engl J Med. 319 [16], (2012). Ref Type: Electronic Citation, 1033-1039.

[127] Ron, E, \& Modan, B. Boice JDJr. Mortality after radiotherapy for ringworm of the scalp. Am J Epidemiol. 127 [4], (1988). Ref Type: Electronic Citation, 713-725.

[128] Shore, R. E, Albert, R. E, \& Pasternack, B. S. Follow-up study of patients treated by Xray epilation for Tinea capitis; resurvey of post-treatment illness and mortality experience. Arch Environ Health 31 [1], (1976). Ref Type: Electronic Citation, 21-28.

[129] Hardell, L, Mild, K. H, Pahlson, A, \& Hallquist, A. Ionizing radiation, cellular telephones and the risk for brain tumours. Eur J Cancer Prev. 10 [6], (2001). Ref Type: Electronic Citation, 523-529.

[130] Thierry-chef, I, Simon, S. L, \& Miller, D. L. Radiation dose and cancer risk among pediatric patients undergoing interventional neuroradiology procedures. Pediatr Radiol (2006). Suppl 2):159-162.

[131] Mezei, G, Gadallah, M, \& Kheifets, L. Residential magnetic field exposure and childhood brain cancer: a meta-analysis. Epidemiology (2008). , 19(3), 424-430.

[132] Gurney, J. G, \& Van Wijngaarden, E. Extremely low frequency electromagnetic fields (EMF) and brain cancer in adults and children: review and comment. Neuro Oncol (1999). , 1(3), 212-220.

[133] Kheifets, L, Sussman, S. S, \& Preston-martin, S. Childhood brain tumors and residential electromagnetic fields (EMF). Rev Environ Contam Toxicol (1999). , 159, 111-129.

[134] Kheifets, L. Electric and magnetic field exposure and brain cancer: a review. Bioelectromagnetics (2001). Suppl 5):SS131., 120.

[135] Neutra, R. R. Panel exploring pro and con arguments as to whether EMFs cause childhood brain cancer. Bioelectromagnetics (2001). Suppl 5):SS149., 144.

[136] Savitz, D. A, Wachtel, H, Barnes, F. A, John, E. M, \& Tvrdik, J. G. Case-control study of childhood cancer and exposure to 60-Hz magnetic fields. Am J Epidemiol (1988). , 128(1), 21-38.

[137] Savitz, D. A, John, E. M, \& Kleckner, R. C. Magnetic field exposure from electric appliances and childhood cancer. Am J Epidemiol (1990). , 131(5), 763-773.

[138] Savitz, D. A, \& Kaune, W. T. Childhood cancer in relation to a modified residential wire code. Environ Health Perspect (1993). , 101(1), 76-80.

[139] Kheifets, L, Ahlbom, A, Crespi, C. M, et al. A pooled analysis of extremely low-frequency magnetic fields and childhood brain tumors. Am J Epidemiol. 172 [7], (2010). Ref Type: Electronic Citation, 752-761.

[140] Wertheimer, N, \& Leeper, E. Electrical wiring configurations and childhood cancer. Am J Epidemiol. 109 [3], (1979). Ref Type: Electronic Citation, 273-284. 
[141] Tomenius, L. Hz electromagnetic environment and the incidence of childhood tumors in Stockholm County. Bioelectromagnetics 7 [2], 191-207. (1986). Ref Type: Electronic Citation, 50.

[142] Preston-martin, S, Gurney, J. G, Pogoda, J. M, Holly, E. A, \& Mueller, B. A. Brain tumor risk in children in relation to use of electric blankets and water bed heaters. Results from the United States West Coast Childhood Brain Tumor Study. Am J Epidemiol (1996). , 143(11), 1116-1122.

[143] Feychting, M, \& Ahlbom, A. Magnetic fields and cancer in children residing near Swedish high-voltage power lines. Am J Epidemiol. 138 [7], (1993). Ref Type: Electronic Citation, 467-481.

[144] Habash, R. W, Elwood, J. M, Krewski, D, Lotz, W. G, Mcnamee, J. P, \& Prato, F. S. Recent advances in research on radiofrequency fields and health: J Toxicol Environ Health B Crit Rev. 12 [4], 250-288. (2009). Ref Type: Electronic Citation, 2004-2007.

[145] Miller, A. B, \& Green, L. M. Electric and magnetic fields at power frequencies. Miller AB, Green LM. Chronic Dis Can (2010). Suppl 1):69-83.

[146] Wood, A. W. Computer screens and brain cancer. Australas Phys Eng Sci Med (1995). , 18(4), 167-176.

[147] Mutnick, A, \& Muscat, J. E. Primary brain cancer in adults and the use of common household appliances: a case-control study. Rev Environ Health. 12 [1], (1997). Ref Type: Electronic Citation, 59-62.

[148] Tworoger, S. S, Davis, S, Schwartz, S. M, \& Mirick, D. K. Stability of WertheimerLeeper wire codes as a measure of exposure to residential magnetic fields over a to 11-year interval. J Expo Anal Environ Epidemiol. 12 [6], 448-454. (2002). Ref Type: Electronic Citation, 9.

[149] Armstrong, B. G, Deadman, J, \& Mcbride, M. L. The determinants of Canadian children's personal exposures to magnetic fields. Bioelectromagnetics 22 [3], (2001). Ref Type: Electronic Citation, 161-169.

[150] Wertheimer, N, \& Leeper, E. Re: "Risk of premenopausal breast cancer and use of electric blankets" and "Use of electric blankets and risk of postmenopausal breast cancer". Am J Epidemiol. 142 [12], (1995). Ref Type: Electronic Citation, 1344-1345.

[151] Wertheimer, N, \& Leeper, E. Bias in studies of electromagnetic fields. J Clin Epidemiol. 47 [9], (1994). Ref Type: Electronic Citation, 1081-1083.

[152] Jensen, J. K, Olsen, J. H, \& Folkersen, E. Assessment of exposure to EMF in a Danish case-control study of childhood cancer. Rev Environ Health 10 [(3-4)], (1994). Ref Type: Electronic Citation, 187-195. 
[153] Kaune, W. T, \& Zaffanella, L. E. Assessing historical exposures of children to powerfrequency magnetic fields. J Expo Anal Environ Epidemiol. 4 [2], (1994). Ref Type: Electronic Citation, 149-170.

[154] Kheifets, L, Bowman, J. D, Checkoway, H, et al. Future needs of occupational epidemiology of extremely low frequency electric and magnetic fields: review and recommendations. Occup Environ Med. 66 [2], (2009). Ref Type: Electronic Citation, 72-80.

[155] Swerdlow, A. J, Feychting, M, \& Green, A. C. Leeka Kheifits LK, Savitz DA, International Commission for Non-Ionizing Radiation Protection Standing Committee on Epidemiology. Mobile phones, brain tumors, and the interphone study: where are we now? Environ Health Perspect. 119 [11], (2011). Ref Type: Electronic Citation, 1534-1538.

[156] Hardell, L, Nasman, A, Pahlson, A, \& Hallquist, A. Hansson Mild K. Use of cellular telephones and the risk for brain tumours: A case-control study. Int J Oncol. 15 [1], (1999). Ref Type: Electronic Citation, 113-116.

[157] Hardell, L, \& Carlberg, M. Hansson Mild K. Pooled analysis of case-control studies on malignant brain tumours and the use of mobile and cordless phones including living and deceased subjects. Int J Oncol. 38 [5], (2011). Ref Type: Electronic Citation, 1465-1474.

[158] Hardell, L, \& Carlberg, M. Hansson Mild K. Mobile phone use and the risk for malignant brain tumors: a case-control study on deceased cases and controls. Neuroepidemiology 35 [2], (2010). Ref Type: Electronic Citation, 109-114.

[159] Cardis, E, Richardson, L, Deltour, I, et al. The INTERPHONE study: design, epidemiological methods, and description of the study population. Eur J Epidemiol. 22 [9], (2007). Ref Type: Electronic Citation, 647-664.

[160] Schuz, J, Bohler, E, Berg, G, et al. Cellular phones, cordless phones, and the risks of glioma and meningioma (Interphone Study Group, Germany). Am J Epidemiol. 163 [6], (2006). Ref Type: Electronic Citation, 512-520.

[161] Blettner, M, Schlehofer, B, Samkange-zeeb, F, Berg, G, Schlaefer, K, \& Schuz, J. Medical exposure to ionising radiation and the risk of brain tumours: Interphone study group, Germany. Eur J Cancer 43 [13], (2007). Ref Type: Electronic Citation, 1990-1998.

[162] Hours, M, Bernard, M, Montestrucq, L, et al. Cell Phones and Risk of brain and acoustic nerve tumours: the French INTERPHONE case-control study]. [Article in French]. Rev Epidemiol Sante Publique. 55 [5], (2012). Ref Type: Electronic Citation, 321-332. 
[163] Lonn, S, Ahlbom, A, Hall, P, \& Feychting, M. Swedish Interphone Study Group. Long-term mobile phone use and brain tumor risk. Am J Epidemiol. 161 [6], (2005). Ref Type: Electronic Citation, 526-535.

[164] Takebayashi, T, Akiba, S, Kikuchi, Y, et al. Mobile phone use and acoustic neuroma risk in Japan. Occup Environ Med. 63 [12], (2006). Ref Type: Electronic Citation, 802-807.

[165] Sadetzki, S, Chetrit, A, Jarus-hakak, A, et al. Cellular phone use and risk of benign and malignant parotid gland tumors--a nationwide case-control study. Am J Epidemiol. 167 [4], (2008). Ref Type: Electronic Citation, 457-467.

[166] Cardis, E, Deltour, I, Vrijheid, M, et al. Brain tumour risk in relation to mobile telephone use: results of the INTERPHONE international case-control study. INTERPHONE Study Group. Int J Epidemiol. 39 [3], (2010). Ref Type: Electronic Citation, 675-694.

[167] Cardis, E, Armstrong, B. K, Bowman, J. D, et al. Risk of brain tumours in relation to estimated RF dose from mobile phones: results from five Interphone countries. Occup Environ Med. 68 [9], (2011). Ref Type: Electronic Citation, 631-640.

[168] Schoemaker, M. J, Swerdlow, A. J, Ahlbom, A, et al. Mobile phone use and risk of acoustic neuroma: results of the Interphone case-control study in five North European countries. Br J Cancer 93 [7], (2005). Ref Type: Electronic Citation, 842-848.

[169] Cardis, E, Deltour, I, Vrijheid, M, et al. Acoustic neuroma risk in relation to mobile telephone use: results of the INTERPHONE international case-control study. INTERPHONE Study Group. Cancer Epidemiol. 35 [5], (2011). Ref Type: Electronic Citation, 453-464.

[170] Kundi, M. Mobile phone use and brain cancer: is the association biased? Neuroepidemiology (2010). , 35(2), 115-116.

[171] Olsen, J. The interphone study: brain cancer and beyond. Bioelectromagnetics (2011). , 32(2), 164-167.

[172] Hardell, L. Hansson Mild K. Mobile phone use and risk of acoustic neuroma: results of the interphone case-control study in five North European countries. Br J Cancer 94 [9], (2006). Ref Type: Electronic Citation, 1348-1349.

[173] Hardell, L, \& Carlberg, M. Hansson Mild K. Epidemiological evidence for an association between use of wireless phones and tumor diseases. Pathophysiology 16 [(2-3)], (2009). Ref Type: Electronic Citation, 113-122.

[174] Little, M. P, Rajaraman, P, Curtis, R. E, et al. Mobile phone use and glioma risk: comparison of epidemiological study results with incidence trends in the United States. BMJ.2012 Mar 8;344:e1147.doi:bmj.e1147. (2012). Ref Type: Electronic Citation 
[175] Sarasua, S, \& Savitz, D. A. Cured and broiled meat consumption in relation to childhood cancer: Denver, Colorado (United States). Cancer Causes Control (1994). , 5(2), 141-148.

[176] Bunin, G. R, Kuitjen, R. R, Boesel, C. P, Buckley, J. D, \& Meadows, A. T. Maternal diet and risk of astrocytic glioma in children: a report from the Childrens Cancer Group (United States and Canada). Cancer Causes Control 5 [2], (1994). Ref Type: Electronic Citation, 177-187.

[177] Bunin, G. R, Kuitjen, R. R, Buckley, J. D, Rorke, L. B, \& Meadows, A. T. Relation between maternal diet and subsequent primitive neuroectodermal brain tumors in young children. N Engl J Med. 329 [8], (1993). Ref Type: Electronic Citation, 536-541.

[178] Forman, D. Commentary: Nitrites, nitrates and nitrosation as causes of brain cancer in children: epidemiological challenges. Int J Epidemiol (2004). , 33(6), 1216-1218.

[179] Khuder, S. A, Mutgi, A. B, \& Schaub, E. A. Meta-analyses of brain cancer and farming. Am J Ind Med (1998). , 34(3), 252-260.

[180] Clapp, R. W, Jacobs, M. M, \& Loechler, E. L. Environmental and occupational causes of cancer: new evidence 2005-2007. Rev Environ Health (2008). , 23(1), 1-37.

[181] Daniels, J. L, Olshan, A. F, \& Savitz, D. A. Pesticides and childhood cancers. Environ Health Perspect (1997). , 105(10), 1068-1077.

[182] Shim, Y. K, Mlynarek, S. P, \& Wijngaarden, E. Parental exposure to pesticides and childhood brain cancer: U.S. Atlantic coast childhood brain cancer study. Environ Health Perspect (2009). , 117(6), 1002-1006.

[183] Van Wijngaarden, E, Stewart, P. A, Olshan, A. F, Savitz, D. A, \& Bunin, G. R. Parental occupational exposure to pesticides and childhood brain cancer. Am J Epidemiol (2003). , 157(11), 989-997.

[184] Davis, J. R, Brownson, R. C, Garcia, R, Bentz, B. J, \& Turner, A. Family pesticide use and childhood brain cancer. Arch Environ Contam Toxicol (1993). , 24(1), 87-92.

[185] Leiss, J. K, \& Savitz, D. A. Home pesticide use and childhood cancer: a case-control study. Am J Public Health 85 [2], (1995). Ref Type: Electronic Citation, 249-252.

[186] Inskip, P. D, Linet, M. S, \& Heineman, E. F. Etiology of brain tumors in adults. Epidemiol Rev. 17 [2], (1995). Ref Type: Electronic Citation, 382-414.

[187] Heineman, E. F, Ward, M. H, Mccomb, R. D, Weisenburger, D. D, \& Zahm, S. H. Hair dyes and risk of glioma among Nebraska women. Cancer Causes Control (2005). , 16(7), 857-864.

[188] Efird, J. T, Holly, E. A, Cordier, S, et al. Beauty product-related exposures and childhood brain tumors in seven countries: results from the SEARCH International Brain Tumor Study. J Neurooncol. 72 [2], (2005). Ref Type: Electronic Citation, 133-147. 
[189] Choi, H. S, Shim, Y. K, Kaye, W. E, \& Ryan, P. B. Potential residential exposure to toxics release inventory chemicals during pregnancy and childhood brain cancer. Environ Health Perspect (2006). , 114(7), 1113-1118.

[190] Mckean-cowden, R, Preston-martin, S, Pogoda, J. M, Holly, E. A, Mueller, B. A, \& Davis, R. L. Parental occupation and childhood brain tumors: astroglial and primitive neuroectodermal tumors. J Occup Environ Med. 40 [4], (1998). Ref Type: Electronic Citation, 332-340.

[191] Savitz, D. A, \& Chen, J. H. Parental occupation and childhood cancer: review of epidemiologic studies. Environ Health Perspect (1990).

[192] Colt, J. S, \& Blair, A. Parental occupational exposures and risk of childhood cancer. Environ Health Perspect. 106 [Suppl 3], (1998). Ref Type: Electronic Citation, 909-925.

[193] Ali, R, Yu, C. L, Wu, M. T, et al. A case-control study of parental occupation, leukemia, and brain tumors in an industrial city in Taiwan. J Occup Environ Med. 46 [9], (2004). Ref Type: Electronic Citation, 985-992.

[194] Mutanen, P, \& Hemminki, K. Childhood cancer and parental occupation in the Swedish Family-Cancer Database. J Occup Environ Med. 43 [11], (2001). Ref Type: Electronic Citation, 952-958.

[195] Cordier, S, Mandereau, L, Preston-martin, S, et al. Parental occupations and childhood brain tumors: results of an international case-control study. Cancer Causes Control 12 [9], (2001). Ref Type: Electronic Citation, 865-874.

[196] Cordier, S, Lefeuvre, B, Filippini, G, et al. Parental occupation, occupational exposure to solvents and polycyclic aromatic hydrocarbons and risk of childhood brain tumors (Italy, France, Spain). Cancer Causes Control 8 [5], (1997). Ref Type: Electronic Citation, 688-697.

[197] Mazumdar, M, Liu, C. Y, Wang, S. F, et al. No association between parental or subject occupation and brain tumor risk. Cancer Epidemiol Biomarkers Prev. 17 [7], (2008). Ref Type: Electronic Citation, 1835-1837.

[198] Rosso, A. L, Hovinga, M. E, Rorke-adams, L. B, Spector, L. G, \& Bunin, G. R. Children's Oncology Group. A case-control study of childhood brain tumors and fathers' hobbies: a Children's Oncology Group study. Cancer Causes Control 19 [10], (2008). Ref Type: Electronic Citation, 1201-1207.

[199] Samuelson, S. O, Bakketeig, L. S, Tretli, S, Johannesen, T. B, \& Magnus, P. Head circumference at birth and risk of brain cancer in childhood: a population-based study. Lancet Oncol (2006). , 7(1), 39-42.

[200] Maule, M, Scelo, G, Pastore, G, et al. Risk of second malignant neoplasms after childhood leukemia and lymphoma: an international study. J Natl Cancer Inst (2007). , 99(10), 790-800. 
[201] Monteiro, G. T, Pereira, R. A, Koifman, R. J, \& Koifman, S. Head injury and brain tumours in adults: A case-control study in Rio de Janeiro, Brazil. Eur J Cancer (2006). , 42(7), 917-921.

[202] Bille, C, Winther, J. F, Bautz, A, Murray, J. C, Olsen, J, \& Christensen, K. Cancer risk in persons with oral cleft--a population-based study of 8,093 cases. Am J Epidemiol (2005). , 161(11), 1047-1055.

[203] Mcbride, M. L. Childhood cancer and environmental contaminants. [Article in English, French]. Can J Public Health 89 [Suppl 1], SS62. (1998). Ref Type: Electronic Citation, 53 .

[204] Kuitjen, R. R, Bunin, G, Nass, C. C, \& Meadows, A. T. Gestational and familial risk factors for childhood astrocytoma: results of a case-control study. Cancer Res. 50 [9], (1990). Ref Type: Electronic Citation, 2608-2612.

[205] Stalberg, K, Haglund, B, Stromberg, B, \& Kieler, H. Prenatal exposure to medicines and the risk of childhood brain tumor. Cancer Epidemiol. 34 [4], (2010). Ref Type: Electronic Citation, 400-404.

[206] Scheurer, M. E, Amirian, E. S, Davlin, S. L, Rice, T, Wrensch, M, \& Bondy, M. L. Effects of antihistamine and anti-inflammatory medication use on risk of specific glioma histologies. Int J Cancer 129 [9], (2011). Ref Type: Electronic Citation, 2290-2296. 